\title{
Violation of Ekman Balance in the Eastern Pacific ITCZ Boundary Layer
}

\author{
Alex O. GonZalez \\ Department of Geological and Atmospheric Sciences, Iowa State University, Ames, Iowa \\ WAYNE H. SCHUBERT \\ Department of Atmospheric Science, Colorado State University, Fort Collins, Colorado
}

(Manuscript received 27 September 2018, in final form 17 May 2019)

\begin{abstract}
The intertropical convergence zone (ITCZ) is one of the most striking features of Earth's climate system, often forming a narrow band of convection over many oceanic regions, especially in eastern ocean basins. It is not well understood why the ITCZ is so thin; however, a recent study highlighted that classical Ekman balance is not obeyed near the equator and nonlinear horizontal wind advection can localize ITCZ boundary layer vertical motion so that it becomes very narrow and intense. In this study, we use a similar model but with more realistic forcings from the Year of Tropical Convection (YOTC) reanalysis, focusing on the eastern Pacific Ocean ITCZ. The model is a zonally symmetric, slab (subcloud) boundary layer numerical model on the sphere, which can be considered the simplest "dry" model of the ITCZ. Due to the slab model's simplicity, simulations are conducted at a range of resolutions, from $1^{\circ}$ to $1 \mathrm{~km}$. The slab model dynamical fields are in general agreement with the YOTC dynamical fields and precipitation estimates from the Tropical Rainfall Measuring Mission for one summer and two spring ITCZ cases. We find that Ekman balance is indeed violated within $10^{\circ}-15^{\circ}$ of the equator and nonlinear horizontal wind advection is crucial to understanding the preferential location, width, and intensity of the eastern Pacific ITCZ. Additionally, it appears that these boundary layer processes involved in ITCZ intensification and narrowing are dependent on model resolution such that present-day general circulation models likely cannot sufficiently resolve them.
\end{abstract}

\section{Introduction}

The intertropical convergence zone (ITCZ) is an east-west-oriented convective belt that wraps nearly around the tropics and produces some of Earth's most intense precipitation. It is a main player in the global hydrologic cycle in addition to being coupled to the Hadley circulation. The ITCZ does not strictly follow the seasonal cycle of maximum insolation, particularly over the ocean; it varies considerably as a function of ocean basin and season due to many complex processes, making it difficult to formulate a comprehensive theory answering fundamental questions, such as, "Why is the ITCZ never observed poleward of $30^{\circ}$ ?" Also, "Why is the ITCZ narrow in eastern ocean basins?" Modeling the ITCZ with sufficient accuracy has proven to be difficult for current-day general circulation models (GCMs) (Stanfield et al. 2016), particularly in the eastern Pacific Ocean, where GCMs tend

\footnotetext{
Corresponding author: Alex O. Gonzalez, agon@iastate.edu
}

to oversimulate a double ITCZ (Mechoso et al. 1995; Lin 2007; Zhang et al. 2015).

Over the eastern Pacific, a single ITCZ is frequently located in the Northern Hemisphere, as shown in Fig. 1, a GOES visible-infrared blended image of the Pacific Ocean on 24 November 2010. This image is quite remarkable because the ITCZ forms a well-defined east-west convective line at nearly the same latitude across the entire ocean basin. At the same time, there are mesoscale and synoptic-scale features embedded within the banded convection. It could be said that the ITCZ is a "mesoscale power plant" with a planetary-scale supporting structure in the Hadley circulation, in a similar vein as stated by Ooyama (1997) regarding tropical cyclones. Over the eastern Pacific, the mesoscale power plant is often very localized, and hence the rising branch of the Hadley circulation is narrow (Charney 1969).

The topic of narrow ITCZs was recently explored by Gonzalez et al. (2016) using a slab boundary layer model on

Publisher's Note: This article was revised on 27 September 2019 to include the correct Fig. 6, which was inadvertently omitted when originally published. 


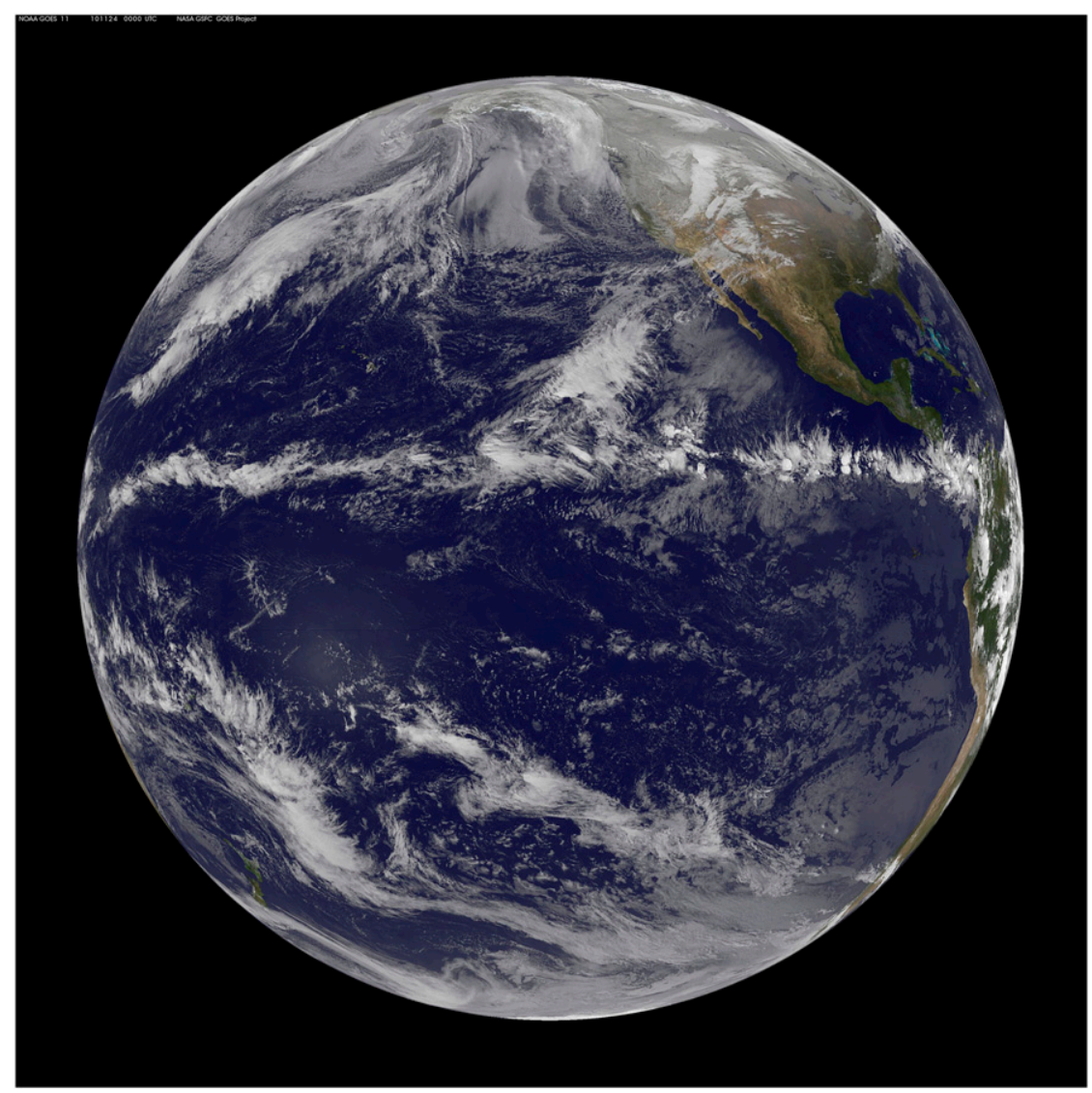

FIG. 1. NOAA GOES-15 visible-infrared blended image of the Pacific Ocean at 0000 UTC 24 Nov 2010. Note the zonal extent and narrowness of the ITCZ. Courtesy of NASA Goddard Space Flight Center.

the equatorial $\beta$ plane. They illustrated the importance of horizontal wind advection in forming narrow regions of boundary layer convergence. When the boundary layer meridional flow is strong, as is often the case in the boundary layer near the ITCZ, the neglect of these advective terms (e.g., as in classical Ekman balance) is not justifiable. With the inclusion of these terms in the boundary layer dynamics, sharp horizontal gradients and sometimes shocklike structures, or near discontinuities, can appear in both the zonal and meridional wind fields, and the relative vorticity and boundary layer convergence can become very narrow, which could explain why convection organizes into well-defined east-west bands such as those observed in Fig. 1. The formation of these fine, elongated structures occurs because there is an embedded Burgers equation (Burgers 1948) in the meridional momentum equation. For shocklike structures, the main force balance near the ITCZ in the meridional momentum equation is between the meridional advection of the meridional velocity and the horizontal diffusion, which prevents the meridional velocity from becoming discontinuous and multivalued. For narrow ITCZs off of the equator, the meridional advection of the meridional velocity is balanced by both the pressure gradient acceleration and the Coriolis effect, which when combined are equivalently the Coriolis effect due to the ageostrophic zonal flow. Thus, for narrow ITCZs, such as those in the eastern ocean basins where the meridional winds are strong enough, horizontal wind advection might play a vital role in the narrowing of the boundary layer vertical velocity.

The importance of boundary layer horizontal advection in explaining narrow ITCZs over the ocean has been highlighted by the early studies of Janota (1971), Mahrt (1972a,b), Holton (1975), and the more recent work of Waliser and Somerville (1994), Tomas et al. (1999), Sobel and Neelin (2006), and Schneider and Bordoni (2008). There are also numerous ITCZ studies that focus on boundary layer dynamics but do not stress the role of boundary layer horizontal wind advection, such as Lindzen and Nigam (1987), Stevens et al. (2002), Pauluis (2004), Raymond et al. (2006), and Back and Bretherton (2009). While all of these studies have placed a focus on the boundary layer dynamics of the ITCZ, other 
recent work has emphasized that variations in ITCZ position can be explained by the atmospheric energy balance (Broccoli et al. 2006; Kang et al. 2008; Schneider et al. 2014; Bischoff and Schneider 2014, 2016; Adam et al. 2016a,b; Schneider 2017). The atmospheric energy balance has also been shown to be quite powerful in explaining how the ITCZ's width changes in different climates (e.g., Byrne and Schneider 2016a,b). One main idea of energy balance theories is that the ITCZ lies near the "energy flux equator," where the column-integrated meridional atmospheric energy flux changes sign (Kang et al. 2008). In this framework, the ITCZ shifts equatorward when the cross-equatorial energy flux decreases and it shifts poleward when the cross-equatorial energy flux increases. In addition, Bischoff and Schneider (2014, 2016) and Adam et al. (2016a,b) provide evidence that ITCZ position is inversely proportional to the equatorial net energy input. More specifically, Adam et al. (2016a) illustrate that seasonal variations of the ITCZ are dominated by the cross-equatorial energy flux while interannual ITCZ variations, such as those associated with strong El Niño-Southern Oscillation conditions and double ITCZs, are best described by changes in ocean heat uptake (i.e., equatorial net energy input). To this end, more general theories are emerging that link perturbations of the atmosphere-ocean energy balance to shifts in ITCZ position (Green and Marshall 2017; Schneider 2017; Wei and Bordoni 2018).

This study, similar to Gonzalez et al. (2016), focuses on the dynamics in the subcloud boundary layer, which is a region where dry dynamics can be quite powerful in understanding transient (daily to weekly time scales), nonlinear behavior (e.g., sharp gradients) of the wind fields. We seek to leverage the results of Gonzalez et al. (2016) by using a spherical version of the model in Gonzalez et al. (2016) and forcing it with realistic pressure fields from the YOTC reanalysis that are not symmetric about the equator and not constrained by geostrophic balance. Since we are interested in the ITCZ over the eastern Pacific, understanding the nonlinear dynamics associated with cross-equatorial pressure gradients is of utmost importance. The underlying assumptions of the model are zonal symmetry and a slab, subcloud boundary layer. These assumptions allow for the model to be run at very high spatial resolutions $(\sim 1 \mathrm{~km})$ in a matter of minutes, presenting an opportunity to quantify detailed dynamical features near the ITCZ and how they become more impactful as a function of increasing horizontal resolution. Also, we suggest that one potential step to improving climate model representation of the ITCZ is to improve the representation of the nonlinear boundary layer dynamics of the ITCZ and its surrounding region.
The paper is organized in the following way. Section 2 presents the governing set of partial differential equations for the numerical slab boundary layer model on the sphere. Section 3 discusses the numerical simulations and the pressure gradient forcing from the global reanalysis product, the Year of Tropical Convection (YOTC). In sections 4 and 5, we present numerical solutions of the slab boundary layer model forced by the pressure gradient acceleration fields for the months of July 2008, March 2009, and March 2010. Section 6 shows a detailed comparison between the slab model and YOTC at $0.25^{\circ}$ resolution. Concluding remarks are made in section 7 .

\section{Slab boundary layer model}

Consider zonally symmetric boundary layer motions of an incompressible fluid on the sphere. The frictional boundary layer is assumed to be a subcloud layer with a constant depth $h$. The boundary layer zonal and meridional velocities $u(\phi, t)$ and $v(\phi, t)$ are independent of height between the top of a thin surface layer and height $h$ and the vertical velocity at the top of the boundary layer (height $h$ ) is denoted by $w(\phi, t)$. The governing system of differential equations for the boundary layer variables $u(\phi, t), v(\phi, t)$, and $w(\phi, t)$ is

$$
\begin{aligned}
\frac{\partial u}{\partial t}+v \frac{\partial u}{a \partial \phi}= & \left(2 \Omega \sin \phi+\frac{u \tan \phi}{a}\right) v-c_{D} U \frac{u}{h} \\
& +\frac{w}{h}(1-\alpha)\left(u-u_{\mathrm{OL}}\right)+K \frac{\partial}{a \partial \phi}\left[\frac{\partial(u \cos \phi)}{a \cos \phi \partial \phi}\right],
\end{aligned}
$$

$$
\begin{aligned}
\frac{\partial v}{\partial t}+v \frac{\partial v}{a \partial \phi}= & -\left(2 \Omega \sin \phi+\frac{u \tan \phi}{a}\right) u-c_{D} U \frac{v}{h}-\frac{1}{\rho} \frac{\partial p}{a \partial \phi} \\
& +\frac{w}{h}(1-\alpha)\left(v-v_{\mathrm{OL}}\right)+K \frac{\partial}{a \partial \phi}\left[\frac{\partial(v \cos \phi)}{a \cos \phi \partial \phi}\right] \\
w= & -h \frac{\partial(v \cos \phi)}{a \cos \phi \partial \phi}
\end{aligned}
$$

where $u_{\mathrm{OL}}$ and $v_{\mathrm{OL}}$ are the respective zonal and meridional velocities in the overlying layer above the boundary layer,

$$
\begin{gathered}
\alpha=\left\{\begin{array}{lll}
1 & \text { if } & w \geq 0 \\
0 & \text { if } & w<0
\end{array}\right. \\
U=0.78\left(u^{2}+v^{2}\right)^{1 / 2}
\end{gathered}
$$

is the wind speed at 10-m height (Powell et al. 2003), $\Omega$ and $a$ are Earth's rotation rate and radius, and $K$ is the 

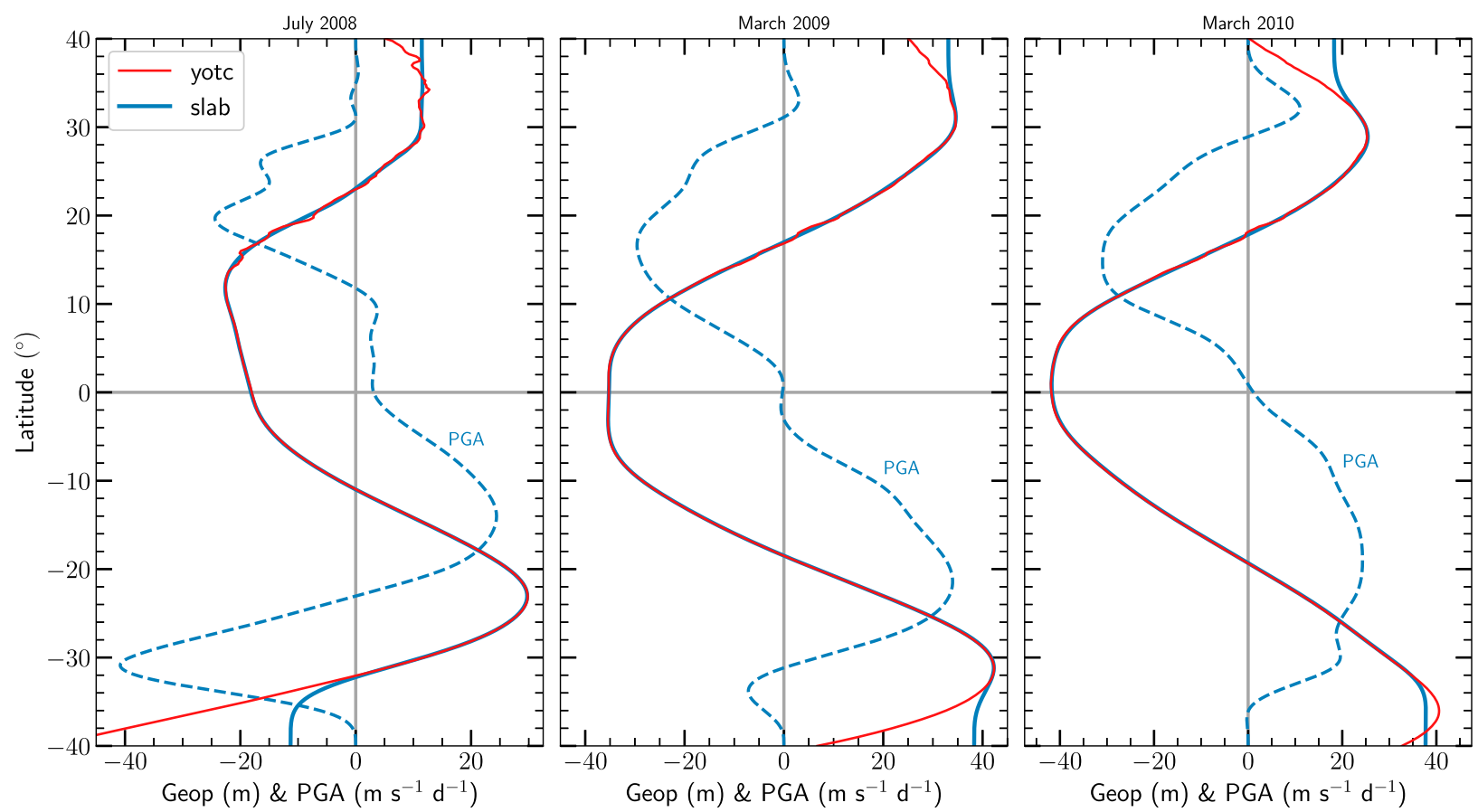

FIG. 2. The YOTC geopotential deviation field $\Phi / g$ (shifted by $350 \mathrm{~m}$ ) averaged over the eastern Pacific boundary layer $\left(85^{\circ}-150^{\circ} \mathrm{W}\right.$, 950-1000 hPa) in raw form (red curves) and interpolated onto the $0.01^{\circ}$ model grid (solid blue curves) for (left) July 2008 , (center) March 2009, and (right) March 2010. The interpolated pressure gradient acceleration is also displayed in the blue dashed curves. Note that all curves are monthly averaged and that the blue curves incorporate a Hann tapering near the north and south boundaries.

constant horizontal diffusivity. The drag factor $c_{D} U$ is assumed to depend on the $10-\mathrm{m}$ wind speed according to

$$
c_{D} U=10^{-3}\left(2.70+0.142 U+0.0764 U^{2}\right),
$$

where $U$ is the $10-\mathrm{m}$ wind speed $\left(\mathrm{m} \mathrm{s}^{-1}\right)$, and where (6) applies for $U \leq 25 \mathrm{~m} \mathrm{~s}^{-1}$ (Large et al. 1994), which is well within the range of the present application $\left(U_{\max } \approx\right.$ $13 \mathrm{~m} \mathrm{~s}^{-1}$ ). The meridional boundary conditions are $u$, $v=0$ at $\phi= \pm 40^{\circ}$, and the initial conditions are

$$
u(\phi, 0)=u_{E}(\phi) \text { and } v(\phi, 0)=v_{E}(\phi)
$$

where $u_{E}(\phi)$ and $v_{E}(\phi)$ are Ekman balanced fields derived from the meridional pressure gradient acceleration in (2). For a detailed derivation of the slab boundary layer equations from first principles, such as absolute angular momentum, see appendix A. For a derivation of the classical Ekman theory equations used to compute the initial conditions (7), see appendix B.

The spherical slab boundary layer equations, (1)-(7), are essentially the same as those in Gonzalez et al. (2016), with this model being on the sphere instead of the equatorial $\beta$ plane. As discussed in Gonzalez et al. (2016), the slab boundary layer equations constitute a hyperbolic system that can be written in characteristic form in the absence of the horizontal diffusion terms. A knowledge of the characteristic form is useful in understanding the formation of very sharp horizontal gradients and shocklike structures.

\section{Numerical simulation details and pressure gradient forcing}

We present numerical simulations of the slab boundary layer model, (1)-(7), forced by the monthly, $85^{\circ}-$ $150^{\circ} \mathrm{W}$, and $950-1000-\mathrm{hPa}$-averaged geopotential field from the YOTC reanalysis for the three months of July 2008, March 2009, and March 2010. These three months are selected due to their contrasting ITCZ behavior in the eastern Pacific (Figs. 2 and 3).

The eastern Pacific is characterized by a single, offequatorial ITCZ in the Northern Hemisphere during all months of the year except boreal spring (Waliser and Gautier 1993). During boreal spring there can be a single ITCZ in either hemisphere or one ITCZ in each hemisphere, which is referred to as a double ITCZ (e.g., Waliser and Gautier 1993; Lietzke et al. 2001; Zhang 2001). July 2008 represents the typically observed single ITCZ in the Northern Hemisphere. March 2009 had modest La Niña conditions (Waliser et al. 2012), which are normally associated with a double ITCZ (Lietzke et al. 2001) or a Southern Hemisphere dominant ITCZ 


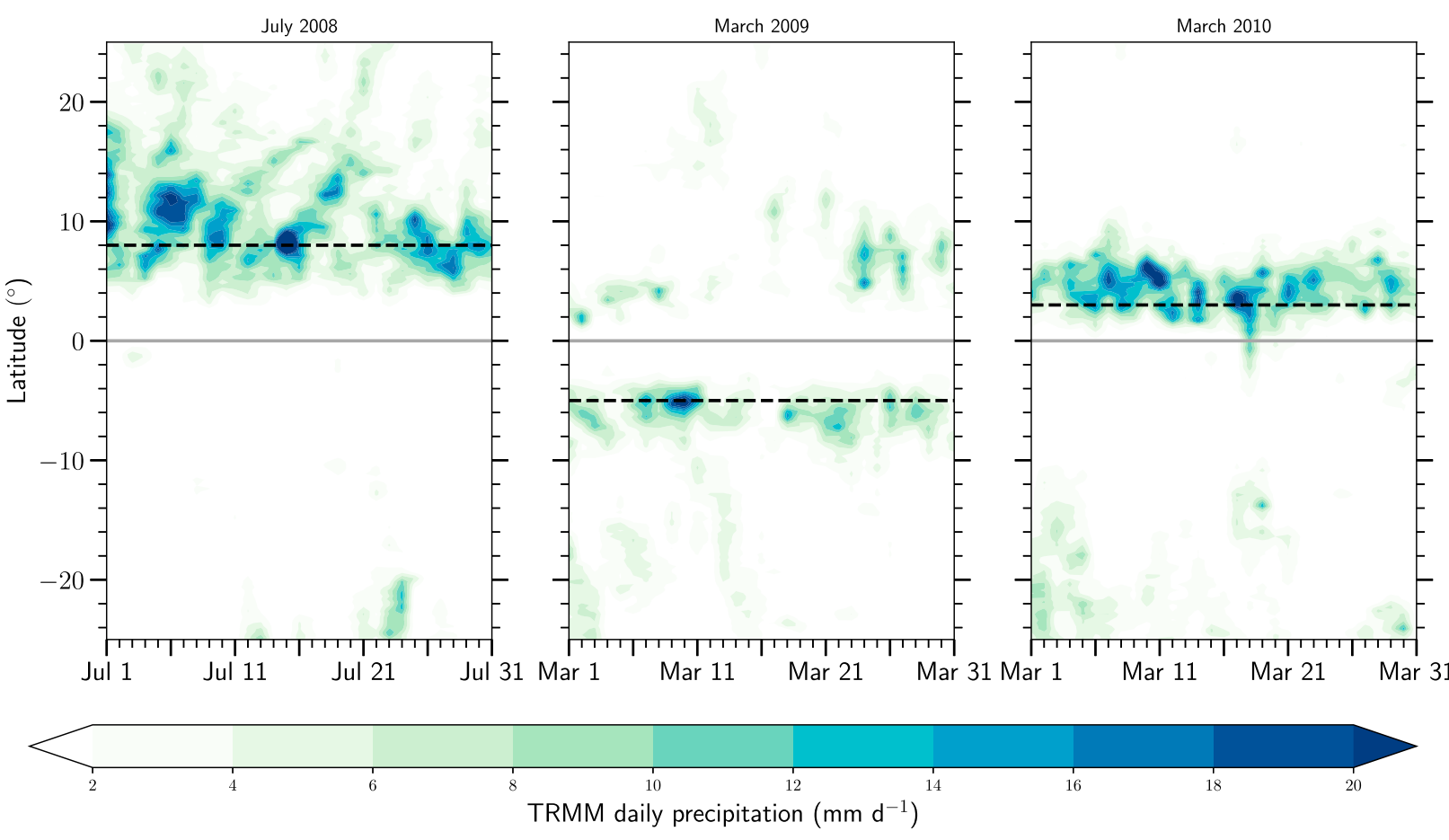

FIG. 3. TRMM daily precipitation over the eastern Pacific $\left(85^{\circ}-150^{\circ} \mathrm{W}\right)$ during (left) July 2008 , (center) March 2009 , and (right) March 2010. Approximate locations of the maximum boundary layer convergence from the $0.01^{\circ}$ slab boundary layer model runs are shown in the black dashed lines.

(Haffke et al. 2016). March 2010 had modest El Niño conditions (Waliser et al. 2012), which are typically associated with a single ITCZ close to the equator (Lietzke et al. 2001; Zhang 2001; Haffke et al. 2016).

The numerical model uses centered, second-order spatial finite difference methods on a meridional domain with a uniform grid spacing; each experiment consists of simulations at four resolutions: $0.01^{\circ}(1.11 \mathrm{~km})$, $0.05^{\circ}(5.56 \mathrm{~km}), 0.25^{\circ}(27.8 \mathrm{~km})$, and $1^{\circ}(111 \mathrm{~km})$. A thirdorder strong-stability-preserving Runge-Kutta time differencing scheme (Gottlieb et al. 2001) is used in place of the standard fourth-order Runge-Kutta scheme to save computational time. The numerical values of other constant parameters, such as time step and Courant-Friedrichs-Lewy (CFL) conditions, are given in Table 1.

The specified boundary layer depth for all simulations is $h=700 \mathrm{~m}$, which is slightly larger than what was used in Gonzalez et al. (2016) $(h=500 \mathrm{~m})$ but is well within the realistic range for the tropical-subtropical eastern Pacific (e.g., Yin and Albrecht 2000; Zeng et al. 2004). The choice for $h$ is based on similar magnitudes between the dynamical fields in the model simulations and the YOTC reanalysis. As discussed in Johnson et al. (2001), $h$ can vary in space and in time depending on numerous environmental factors, such as moisture, wind speed, static stability, and convective activity. Using a temporally or spatially varying $h$ is beyond the scope this study but it is being considered in future simulations using the slab boundary layer model.

The specified forcing for each experiment is the boundary layer pressure gradient acceleration, which is calculated using the geopotential on pressure levels from the YOTC reanalysis (Waliser et al. 2012; ECMWF 2012, accessed 23 March 2017). Even though the specification of the main forcing may seem crude due to the lack of communication of the dynamics back onto the thermodynamics, it is quite powerful because it allows us to understand how our results compare to seminal studies that prescribe similar pressure gradient or temperature gradient forcings (e.g., Lindzen and Nigam 1987; Tomas et al. 1999; Back and Bretherton 2009). YOTC is a global reanalysis product spanning the time period of

TABLE 1. Spatial resolution $\Delta \phi(y=a \phi)$, time step $\Delta t$, horizontal diffusivity $K$, and approximate Courant-Friedrichs-Lewy (CFL) conditions (standard CFL and CFL associated with $K, v_{\max }=$ $10 \mathrm{~m} \mathrm{~s}^{-1}$ ) for the four model resolutions.

\begin{tabular}{crccc}
\hline \hline$\Delta \phi(\Delta y)$ & $\Delta t(\mathrm{~s})$ & $K\left(\mathrm{~m}^{2} \mathrm{~s}^{-1}\right)$ & $v_{\max } \Delta t / \Delta y$ & $K \Delta t /(\Delta y)^{2}$ \\
\hline $1.00^{\circ}(111 \mathrm{~km})$ & 1200 & $1.0 \times 10^{6}$ & 0.11 & 0.10 \\
$0.25^{\circ}(27.8 \mathrm{~km})$ & 300 & $2.5 \times 10^{5}$ & 0.11 & 0.10 \\
$0.05^{\circ}(5.56 \mathrm{~km})$ & 60 & $5.0 \times 10^{4}$ & 0.11 & 0.10 \\
$0.01^{\circ}(1.11 \mathrm{~km})$ & 12 & $1.0 \times 10^{4}$ & 0.11 & 0.10 \\
\hline
\end{tabular}


May 2008-April 2010. It uses four-dimensional variational data assimilation at a horizontal resolution of $0.25^{\circ}$ (T799), with 91 vertical levels. For our present purposes, the YOTC geopotential field has been averaged over longitudes $85^{\circ}-150^{\circ} \mathrm{W}$, pressure levels $950-1000 \mathrm{hPa}$, and the entire month for each experiment. The meridional derivative of the geopotential is calculated using centered, second-order spatial finite difference methods and it is interpolated onto the various slab model grids outlined in Table 1 using the NCAR Command Language (NCL) cubic spline interpolation function csa1xd using 20 knots for the March experiments and 25 knots for the July experiment, where knots are irregularly spaced points. To enforce the boundary conditions $\left(u, v=0\right.$ at $\left.\phi= \pm 40^{\circ}\right)$, the pressure gradient acceleration is also required to vanish at the meridional boundaries. To ensure a smooth transition to zero near these boundaries, we employ a Hann tapering over the $10^{\circ}$ latitude closest to each boundary. Additionally, the zonal and meridional wind components above the boundary layer $u_{\mathrm{OL}}$ and $v_{\mathrm{OL}}$ are interpolated using the NCL cubic spline interpolation function and they are tapered over the $10^{\circ}$ closest to each boundary.

Figure 2 shows the monthly, $85^{\circ}-150^{\circ} \mathrm{W}$, and 950 1000-hPa-averaged YOTC geopotential height field $\Phi / g(\mathrm{~m})$ with and without the interpolation in the red and blue curves, respectively, for the months of July 2008, March 2009, and March 2010. Note that the geopotential field is an anomaly from a reference value of $350 \mathrm{~m}$. The interpolated geopotential fields are very accurate throughout the entire domain for all three months, with the smoothing seen mainly in the region north of about $7^{\circ} \mathrm{N}$ where influences of terrain that peaks above the 950-1000-hPa layer over North and Central America causes there to be slightly irregular behavior. All three months are dominated by the subtropical highs in each hemisphere and low geopotential near the equator, with slight shifts in the strength and position of these features.

The July 2008 geopotential height field is dominated by a stronger subtropical high in the Southern Hemisphere than the one in the Northern Hemisphere and low heights in the $5^{\circ} \mathrm{S}-15^{\circ} \mathrm{N}$ region. The pressure gradient acceleration is positive north of the Southern Hemisphere subtropical high until the geopotential minimum, which occurs near $12^{\circ} \mathrm{N}$. Note that the pressure gradient acceleration is quite small from the equator to $12^{\circ} \mathrm{N}$. As we will see, this relatively small pressure gradient acceleration induces a substantial meridional flow despite the relatively small gradient mainly because the Coriolis parameter is small near the equator. The pressure gradient acceleration is negative from the geopotential minimum to the Northern Hemisphere subtropical high.
Zonally averaged $\left(85^{\circ}-150^{\circ} \mathrm{W}\right)$ precipitation for July 2008, which is displayed in the leftmost panel of Fig. 3, shows that tropical precipitation mainly occurs from $5^{\circ}$ to $15^{\circ} \mathrm{N}$ and is highly variable in time. The precipitation is from the Tropical Rainfall Measuring Mission (TRMM) 3B42, version 7, dataset (Huffman and Bolvin 2015; NASA GSFC 2015, accessed 21 May 2018), where the precipitation rate is calculated from daily accumulated precipitation at a horizontal resolution of $0.25^{\circ}$ in latitude and longitude. Note that there are both southward- and northward-propagating precipitation systems, where the northward-propagating disturbances are typically associated with tropical cyclones. Also displayed in Fig. 3 is the latitude of the maximum boundary layer convergence produced by the slab boundary layer model $0.01^{\circ}$ simulation, which generally coincides with TRMM precipitation.

The horizontal structure of the geopotential height field during March 2009 is best described as being nearly symmetric about the equator, with subtropical highs of similar strength and centered at nearly the same latitude. This approximate meridional symmetry is reflected in the structure of the pressure gradient acceleration, which is mainly positive in the Southern Hemisphere and negative in the Northern Hemisphere. If one looks in more detail near the equator, the pressure gradient acceleration crosses zero just like the March 2010 case, but it hovers around zero and is actually negative from $4^{\circ} \mathrm{S}$ to the equator. Also, the second derivative of the pressure gradient acceleration in this near-equatorial region is different for March 2009 and 2010; the pressure gradient acceleration during March 2009 is convex south of the equator and concave north of the equator with an inflection point in between whereas March 2010 has negligible concavity. We will see that it is this detailed structure in the pressure gradient acceleration that can help in determining whether boreal spring has a double ITCZ or a single, near-equatorial ITCZ. From Fig. 3, tropical precipitation during March 2009 is characterized by a double ITCZ at times and a single ITCZ south of the equator at other times. The ITCZ south of the equator typically had more intense precipitation and this is well represented by the slab boundary layer model, with the maximum boundary layer convergence occurring at $5^{\circ} \mathrm{S}$. To clarify, the slab boundary layer model actually reproduces both ITCZs, but the Southern Hemisphere ITCZ is significantly more intense.

The geopotential height field during March 2010 is very similar to the one seen in March 2009, with some subtle and important differences. For example, the subtropical high in the Southern Hemisphere is located about $5^{\circ}$ S of where it was during March 2009, and the region of low heights is more meridionally confined and 

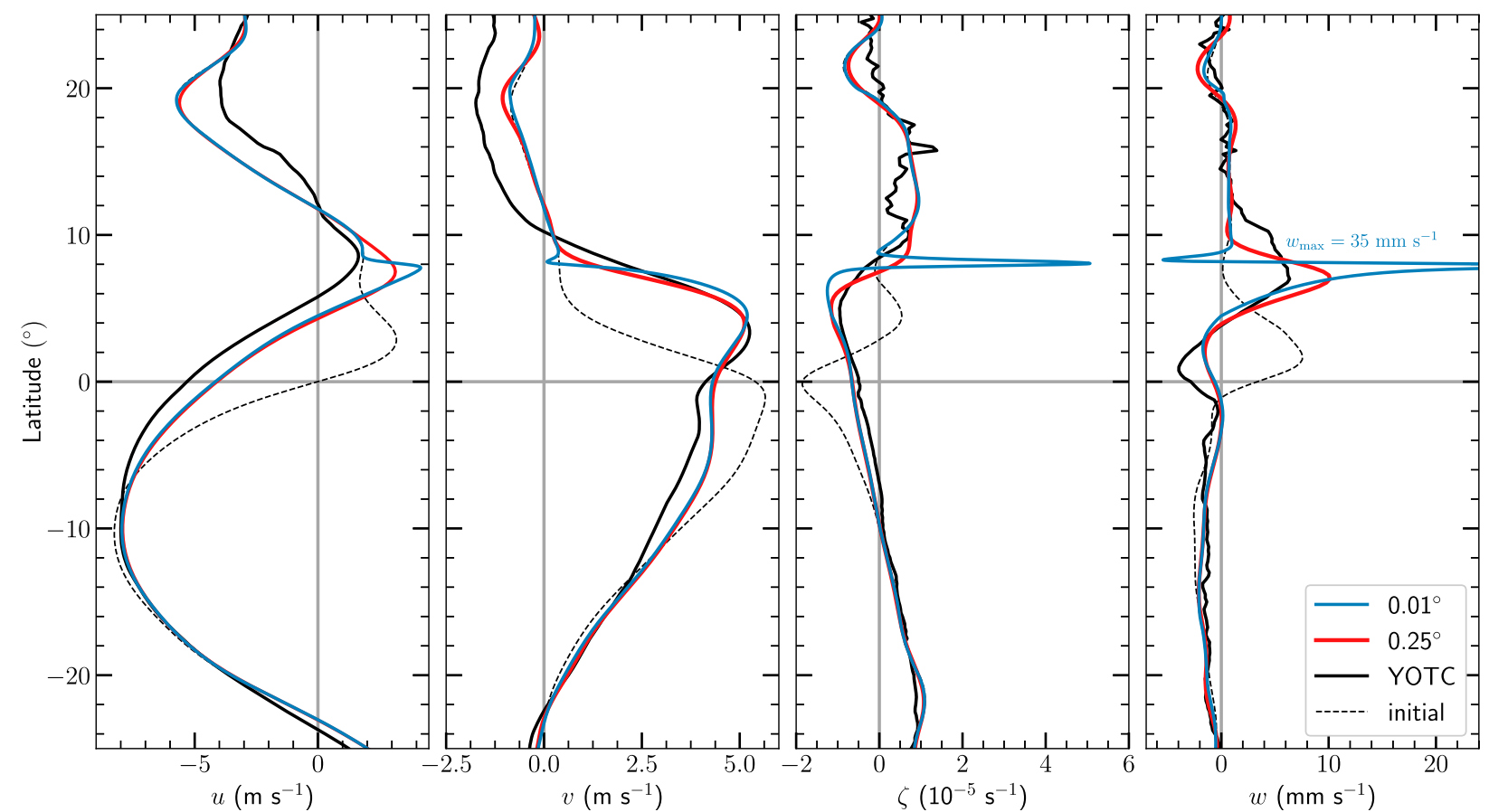

FIG. 4. Quasi-steady-state solutions of the slab boundary layer model at $0.01^{\circ}$ (blue curves) and $0.25^{\circ}$ (red curves) resolution forced by the July 2008 YOTC pressure gradient acceleration. The Ekman balance initial conditions for each field are displayed in the thin black dashed curves; see (B2) and (B3) for details. The July 2008 YOTC fields (averaged over the eastern Pacific boundary layer, $85^{\circ}-150^{\circ} \mathrm{W}$, 950-1000 $\mathrm{hPa}$ ) are represented by the black solid curves.

has shifted slightly north of the equator. These differences between the two March patterns are reflected in the pressure gradient acceleration in that the pressure gradient acceleration is smaller in the Southern Hemisphere from the subtropical high until a few degrees south of the equator where the pressure gradient acceleration is positive in March 2010 rather than negative as it was during March 2009. Also, the pressure gradient acceleration does not hover around zero near the equator but instead crosses zero in a nearly linear fashion (near zero concavity) near $2^{\circ}-3^{\circ} \mathrm{N}$. Due to these slight differences, the March 2010 ITCZ was located near but north of the equator, as seen from the right panel of Fig. 3. Similar to the other two months, the eastern Pacific ITCZ experiences substantial transient activity that can be stationary or propagate meridionally. As we will see, the slab boundary layer model can replicate the single near-equatorial ITCZ conditions observed by TRMM during March 2010 (refer to the dashed black line in the right panel of Fig. 3).

Also, note that the slab boundary layer model simulations for all experiments reach an approximate equilibrium, which is determined by the meridional integral of the kinetic energy and its tendency over the entire domain (not shown), by $t=240 \mathrm{~h}$. Thus, from here on we will refer to this time as the model simulation quasisteady state.

\section{July 2008 experiments}

In the first set of experiments, we compute numerical solutions of the problem (1)-(7) with the specified pressure gradient acceleration from the YOTC reanalysis for the month of July 2008 (Fig. 2). Figure 4 shows the quasi-steady-state slab boundary layer model solutions of $u(\phi, t), v(\phi, t)$, boundary layer relative vorticity $\zeta(\phi, t)=-(\partial u / a \partial \phi)+u \tan \phi / a$, and $w(\phi, t)$ for the $0.01^{\circ}$ simulation in the blue curves and the $0.25^{\circ}$ simulation in the red curves. Also displayed in the solid black curves are the respective monthly YOTC fields over the eastern Pacific boundary layer $\left(85^{\circ}-150^{\circ} \mathrm{W}\right.$, 950-1000 hPa) and the initial conditions for each field in the thin black dashed curves. Recall the initial conditions in (7) correspond to Ekman balance with the prescribed pressure gradient acceleration.

Overall, the steady-state solutions from both the $0.25^{\circ}$ and $0.01^{\circ}$ simulations compare well with the July 2008 YOTC reanalysis fields and the TRMM precipitation estimates, placing the main convergence region near $8^{\circ} \mathrm{N}$ associated with a rapid slowdown in southerly crossequatorial flow. The maximum rising motion in the 
ITCZ in the $0.25^{\circ}$ run is of a similar magnitude $(\approx 5-$ $10 \mathrm{~mm} \mathrm{~s}^{-1}$ ) as YOTC but is more latitudinally confined. The $0.01^{\circ}$ simulation produces an even more localized maximum in vertical velocity, with rising motion nearly one order of magnitude larger $\left(w_{\max }=35 \mathrm{~mm} \mathrm{~s}^{-1}\right)$ than in YOTC. The main reason for this larger vertical velocity is that the $0.01^{\circ}$ simulation produces a sharper meridional gradient of the meridional velocity, not that the meridional velocity is larger. South of the ITCZ, the slab boundary layer model simulations produce generally weak subsidence occurring where the southerly flow increases with latitude (except $2-3^{\circ} \mathrm{S}$ ), which is consistent with YOTC. However, the slab model runs underestimate subsidence in a region just north of the equator where subsidence maximizes in YOTC. The $0.01^{\circ}$ run produces its strongest subsidence in a narrow zone just north of the ITCZ; this feature is absent from the $0.25^{\circ}$ simulation and in YOTC. Based on experience with the slab model in numerous simulations, it is hard to discern whether this behavior is realistic or is a model artifact.

Associated with convergence in the ITCZ, there is a broad region $\left(8^{\circ}-19^{\circ} \mathrm{N}\right)$ of large cyclonic vorticity in the slab model runs and in the YOTC reanalysis. In the $0.01^{\circ}$ run, there is a very narrow region containing large cyclonic vorticity (often referred to as a vorticity "sheet") associated with a rapid decrease in westerly flow at $8^{\circ} \mathrm{N}$. Neither the $0.25^{\circ}$ simulation nor YOTC shows this feature although it is an important feature to point out because it allows the meridional absolute vorticity gradient to reverse in sign, which allows the necessary conditions for barotropic instability to be satisfied (Charney 1969). During boreal summer months, the ITCZ often breaks down due to this instability (Ferreira and Schubert 1997; Wang and Magnusdottir 2006) and it is possible that the ITCZ in the slab model would break down if it were not constrained by zonal symmetry (recall the northward-propagating disturbances from Fig. 3). Just south of the region with large cyclonic vorticity is a region with strong anticyclonic vorticity associated with a sharp increase in westerly flow from south of the ITCZ. This peak in anticyclonic vorticity strengthens as horizontal resolution increases as further supported by Fig. 6 .

Initially in the model runs, $u=u_{E}$ and $v=v_{E}$ so that (1) and (2) can be rewritten as

$$
\frac{\partial u}{\partial t}+v \frac{\partial u}{a \partial \phi}=+\frac{w}{h}(1-\alpha)\left(u-u_{\mathrm{OL}}\right)+K \frac{\partial}{a \partial \phi}\left[\frac{\partial(u \cos \phi)}{a \cos \phi \partial \phi}\right],
$$

$$
\frac{\partial v}{\partial t}+v \frac{\partial v}{a \partial \phi}=+\frac{w}{h}(1-\alpha)\left(v-v_{\mathrm{OL}}\right)+K \frac{\partial}{a \partial \phi}\left[\frac{\partial(v \cos \phi)}{a \cos \phi \partial \phi}\right] \text {. }
$$

If we assume we are in the main convergence region ( $1-\alpha$ terms equal zero), the main terms at play initially for both the zonal and meridional momentum equations, (1) and (2), are the nonlinear horizontal advective terms $v(\partial u / a \partial \phi)$ and $v(\partial v / a \partial \phi)$ and the horizontal diffusion terms. The horizontal advective terms help sharpen horizontal wind gradients near the equator where the meridional winds are sufficiently large initially (see the dashed black curves of Fig. 4) and push the convergence region northward over a period of a few days. The differences between the initial and steady-state fields highlight the northward propagation of the convergence region since the initial fields are in Ekman balance and are therefore void of horizontal advection. The meridional gradient sharpening is well explained by the embedded Burgers equation in (2) as discussed in Gonzalez et al. (2016). The initial broad convergence region essentially convergences onto itself, causing the meridional wind to sharpen as it is advected northward until it becomes nearly discontinuous. Simulation of this process is dependent on horizontal resolution and is thus more effective in the $0.01^{\circ}$ run than the $0.25^{\circ}$ run, as we discuss in more detail later in this section. These sharp gradients are associated with very intense boundary layer rising motion near $5^{\circ}-8^{\circ} \mathrm{N}$ and cyclonic relative vorticity at $8^{\circ} \mathrm{N}$.

Although the $0.25^{\circ}$ and $0.01^{\circ}$ slab boundary layer model runs show qualitative agreement with the YOTC reanalysis, they do show slight deficiencies in the winds north of the ITCZ. The northerlies are approximately half as strong as they are in the YOTC reanalysis and the easterlies are about 1.5 times too strong, as seen from the two leftmost panels of Fig. 4. We believe that these deficiencies would be alleviated if the model were not constrained by the zonal symmetry assumption. In particular, the subtropical high in the Northern Hemisphere induces a large zonal gradient in the meridional winds, with southerlies in the western Pacific and northerlies in the eastern $\mathrm{Pa}$ cific in the subtropics. Since the zonal winds in this region are easterly, $u(\partial v / \partial \lambda)>0$ is associated with $\partial v / \partial t<0$ and a larger northerly flow than what is produced in the zonally symmetric model. At the same time, the zonal gradient of the zonal winds is typically positive, therefore $u(\partial u / \partial \lambda)<0$ and $\partial u / \partial t>0$, which would be associated with weaker easterly flow than what the zonally symmetric slab model produces.

To further assist in our interpretation of the results in Fig. 4, we compute the quasi-steady-state values of the individual terms in (1) and (2). First, we rewrite (1) and (2) in the abbreviated form: 


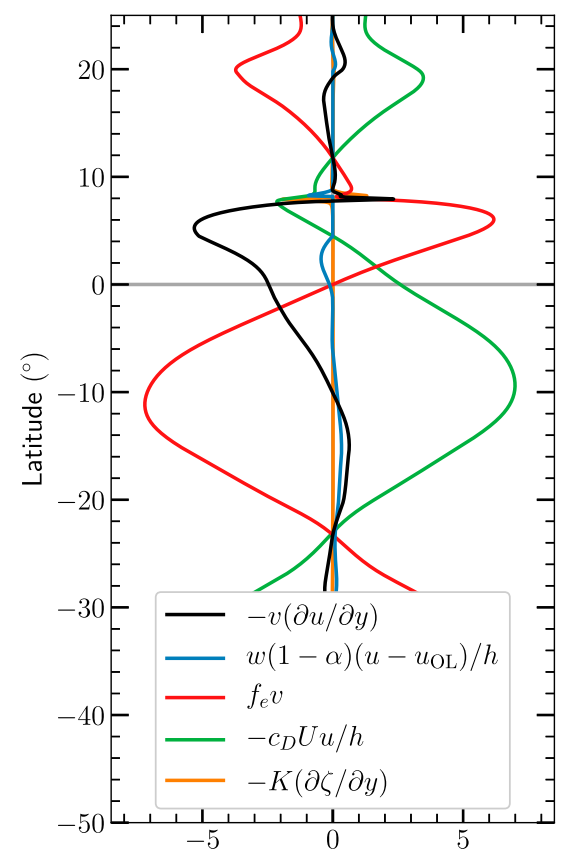

a) $\partial u / \partial t$ terms $\left(\mathrm{m} \mathrm{s}^{-1} \mathbf{d}^{-1}\right)$

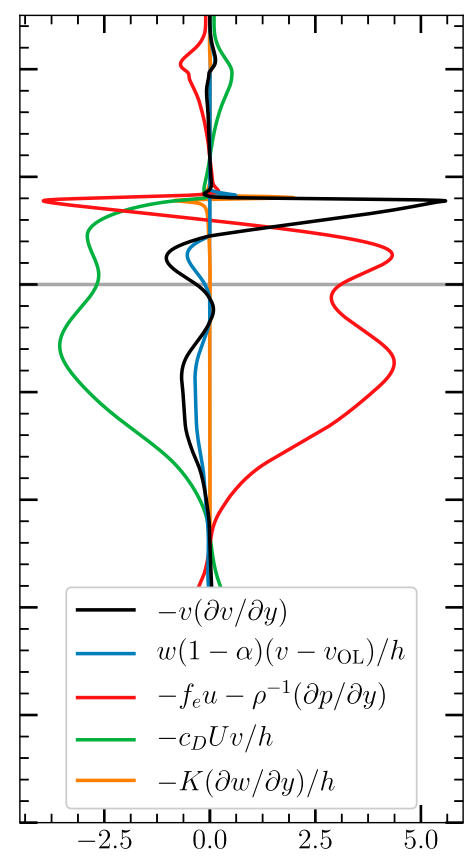

b) $\partial v / \partial t$ terms $\left(\mathrm{m} \mathrm{s}^{-1} \mathrm{~d}^{-1}\right)$

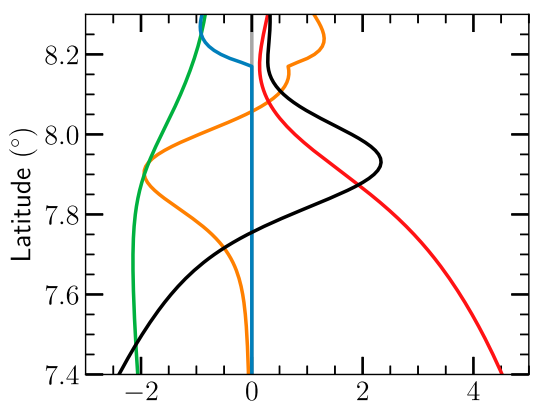

c) $\partial u / \partial t$ terms $\left(\mathrm{m} \mathrm{s}^{-1} \mathbf{d}^{-1}\right)$

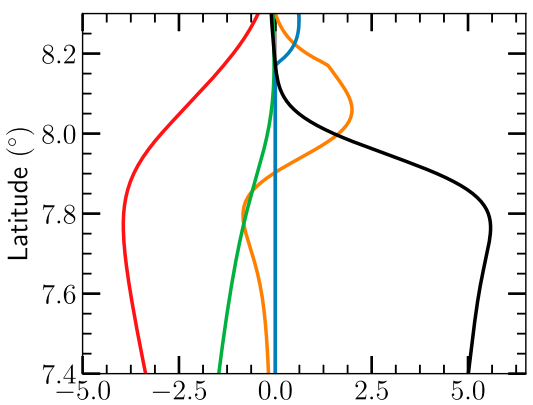

d) $\partial v / \partial t$ terms $\left(\mathrm{m} \mathrm{s}^{-1} \mathrm{~d}^{-1}\right)$

FIG. 5. Quasi-steady-state (a) zonal and (b) meridional momentum budget, i.e., the individual terms on the right-hand sides of (10) and (11), for the July $20080.01^{\circ}$ experiment. (c),(d) Magnification of the regions of sharp gradients $\left(7.4^{\circ}-8.3^{\circ} \mathrm{N}\right)$ in (a) and (b), respectively. Note the shorthand notations $y=a \phi$ and $f_{e}=2 \Omega \sin \phi+u \tan \phi / a$.

$$
\begin{aligned}
\frac{\partial u}{\partial t}= & -v \frac{\partial u}{\partial y}+\frac{w}{h}(1-\alpha)\left(u-u_{\mathrm{OL}}\right)+f_{e} v \\
& -c_{D} U \frac{u}{h}-K \frac{\partial \zeta}{\partial y} \\
\frac{\partial v}{\partial t}= & -v \frac{\partial v}{\partial y}+\frac{w}{h}(1-\alpha)\left(v-v_{\mathrm{OL}}\right)-\left(\frac{1}{\rho} \frac{\partial p}{\partial y}+f_{e} u\right) \\
& -c_{D} U \frac{v}{h}-\frac{K}{h} \frac{\partial w}{\partial y}
\end{aligned}
$$

where $y=a \phi$ and $f_{e}=2 \Omega \sin \phi+u \tan \phi / a$ is an effective Coriolis parameter. We illustrate the horizontal structure of the individual terms on the right-hand sides of (10) and (11) in a quasi-steady state for the $0.01^{\circ}$ simulation in Fig. 5. Note that the Coriolis and pressure gradient acceleration terms from (11) are combined into one term in Fig. 5. Individually, those two terms are significantly larger than the other terms in (11), but are of a comparable magnitude when they are combined. Together they can be thought of as representing the Coriolis effect due to ageostrophic zonal flow; that is, $\rho^{-1}(\partial p / \partial y)+f_{e} u \approx f_{e}\left(u-u_{g}\right)$. Note that the ageostrophic zonal flow is small everywhere except near the equator.

Figure 5 shows that both horizontal diffusion terms are negligible everywhere except in an extremely narrow region where the largest boundary layer pumping and cyclonic vorticity occurs, near $8^{\circ} \mathrm{N}$. In Fig. 5c, it becomes clearer that the horizontal diffusion and $-\left(c_{D} U u / h\right)$ terms balance $v(\partial u / a \partial \phi)$ and $f_{e} v$ near $8^{\circ} \mathrm{N}$ in (10) where the slab model simulates a cyclonic vorticity sheet (e.g., Fig. 4). The main balance in the region from the equator to $8^{\circ} \mathrm{N}$ is between $f_{e} v$ and $v(\partial u / a \partial \phi)$. The rest of the domain is best described as a near balance between zonal surface drag and the Coriolis effect (Fig. 4a, or in other words, Ekman balance. In line with this observation, horizontal advection is significantly smaller in the regions poleward of approximately $10^{\circ}$ latitude.

In Fig. $5 b$, it is seen that $-v(\partial v / a \partial \phi)$ is balanced by the horizontal diffusion term and the combined pressure gradient acceleration and Coriolis term near $8^{\circ} \mathrm{N}$, but mainly the combined pressure gradient and Coriolis acceleration term. This is further confirmed in Fig. $5 \mathrm{~d}$. One can say that the simulated ITCZ for July 2008 is not a shocklike structure since horizontal diffusion is not the main process that counteracts meridional advection in the meridional momentum equation (Gonzalez et al. 2016). Even though the July 2008 ITCZ is not shocklike, it is clear that the classical Ekman theory solutions cannot accurately reproduce the numerical solutions. This is mainly due to the lack of the horizontal advective terms in classical Ekman theory that play the leading role in sharpening and strengthening boundary layer pumping regions and broadening and weakening boundary layer 

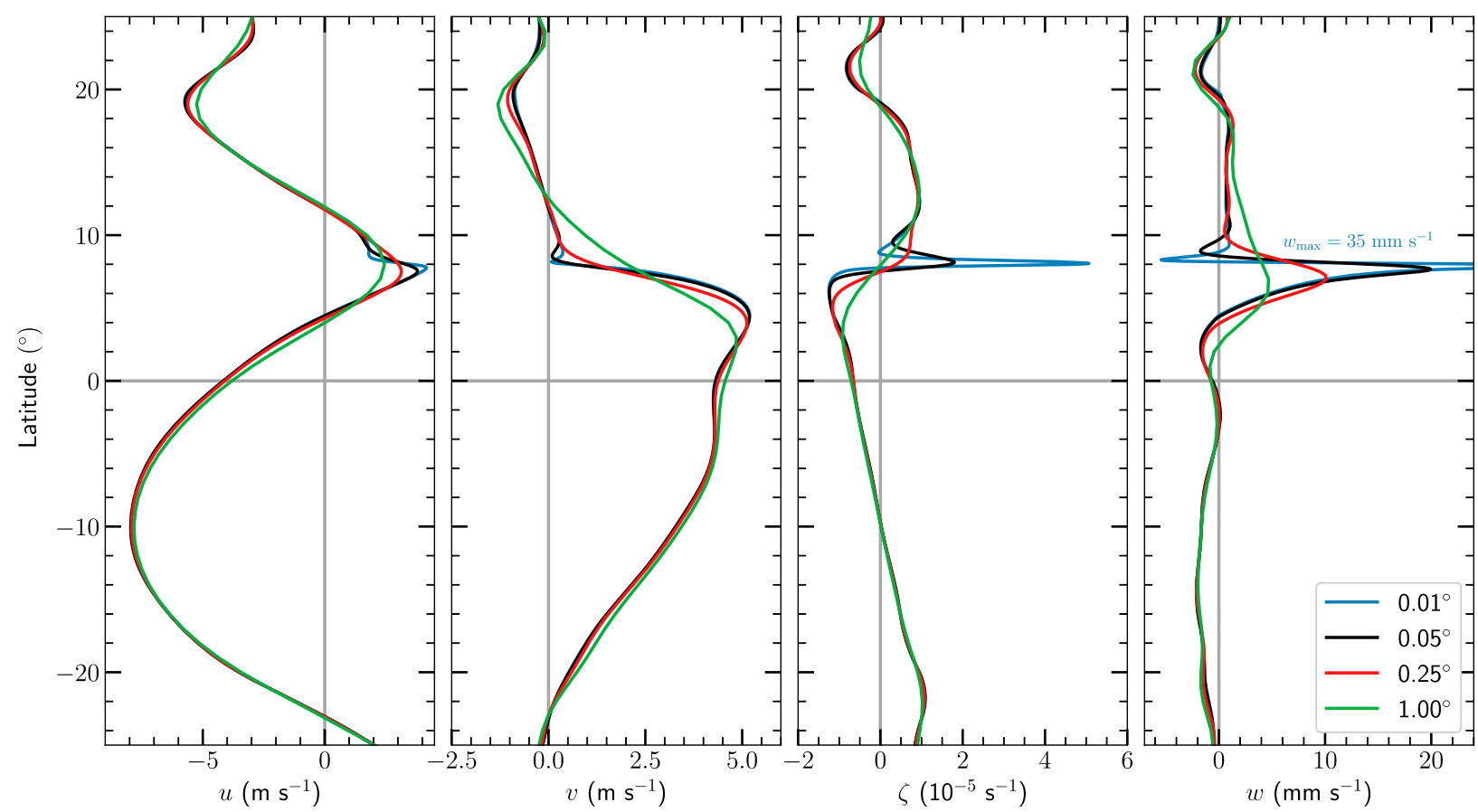

FIG. 6. The slab boundary layer model quasi-steady-state solutions for the July 2008 YOTC forcing at the four horizontal resolutions of $0.01^{\circ}, 0.05^{\circ}, 0.25^{\circ}$, and $1^{\circ}$. For details about the constants used in the different model simulations, refer to Table 1.

suction regions (Gonzalez et al. 2016). For the rest of the domain, especially outside of the main convergence region, it appears that classical Ekman balance is an accurate boundary layer approximation.

\section{Dependence of ITCZ width and strength on horizontal resolution}

A question that naturally arises from these results is, "What horizontal resolution is required to simulate these sharp gradients near the ITCZ?" To address this question, we conduct simulations at four different horizontal resolutions. Figure 6 illustrates the slab boundary layer model quasi-steady-state solutions of $u(\phi, t)$, $v(\phi, t), \zeta(\phi, t)$, and $w(\phi, t)$ for the four model resolutions: $0.01^{\circ}, 0.05^{\circ}, 0.25^{\circ}$, and $1^{\circ}$.

As horizontal resolution increases, the meridional gradient of the meridional velocity increases substantially, particularly near $8^{\circ} \mathrm{N}$, which leads to an increase in upward motion and a concentration of the region of convergence. Note that this does not mean that the magnitude of the meridional wind is larger in the higher-resolution runs, but rather that the gradient simply increases. In the $1^{\circ}$ simulation, the ITCZ can be defined as a very broad region of lightly rising motions from approximately $2^{\circ}$ to $19^{\circ} \mathrm{N}$, with slightly larger vertical velocity near $7^{\circ} \mathrm{N}$. In this case, a convergence "zone" is hard to define; presumably, current-day GCMs rely on their convective parameterization to help localize ITCZ convection.
The zonal winds are quite similar between the simulations everywhere except near the convergence zone $\left(5^{\circ}-10^{\circ} \mathrm{N}\right)$, where westerlies strengthen and the horizontal gradients of the zonal winds increase as horizontal resolution increases. This increase in horizontal gradients leads to a cyclonic vorticity sheet and stronger anticyclonic vorticity in the region just south of the vorticity sheet. As mentioned previously, it is possible that the vorticity sheet plays a role in barotropic instability of the ITCZ, which cannot be represented with this zonally symmetric model. It is also worth noting that inertial instability could occur near the equator since $f(\zeta+f)<0$ (not shown). To better assess these possible instabilities, it would be beneficial to extend the slab boundary layer model to two horizontal dimensions. The authors plan to explore this in future studies.

To improve our understanding of the differences between the model simulations at various resolutions, we examine the meridional momentum budget near the main convergence region, $5^{\circ}-8^{\circ} \mathrm{N}$. Figure 7 shows that as horizontal resolution increases, the role of meridional advection increases. Along with this increase in meridional advection is an increase in the Coriolis effect due to the ageostrophic flow and nonlinear surface drag, which together counteract advection. The ageostrophic zonal flow increases as horizontal resolution increases mainly due to the increase in westerlies south of the ITCZ while surface drag increases because of the increased meridional flow 


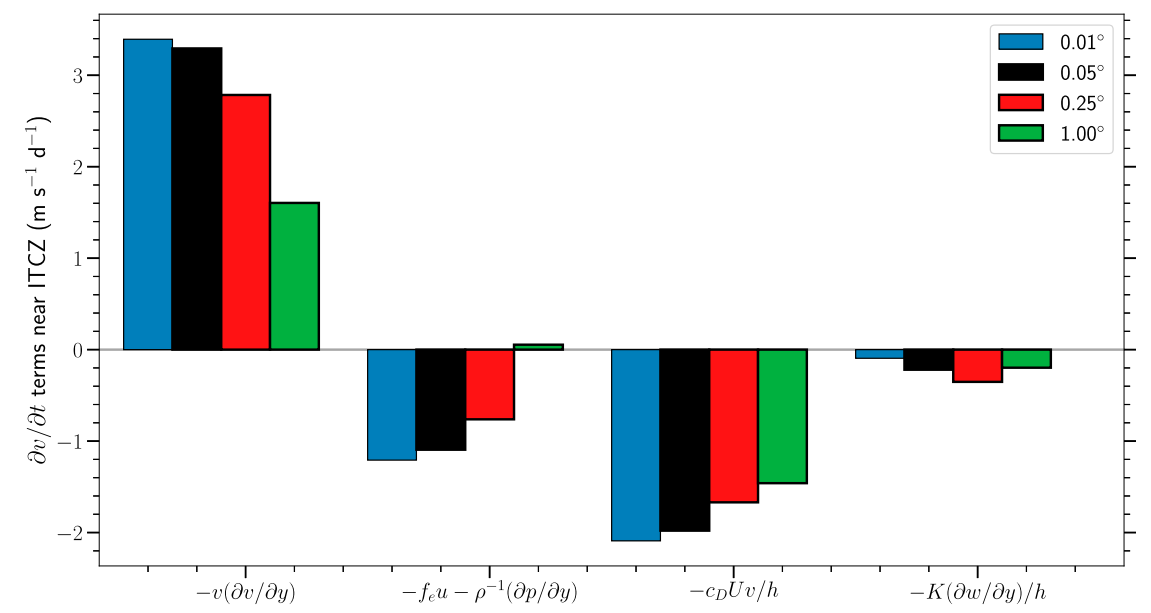

FIG. 7. Latitudinally averaged contributions of the individual terms in the meridional momentum budget, (11), near the region of largest boundary layer convergence $\left(5^{\circ}-8^{\circ} \mathrm{N}\right)$ for the July 2008 experiments in a quasi-steady state: $0.01^{\circ}, 0.05^{\circ}, 0.25^{\circ}$, and $1^{\circ}$.

just south of the ITCZ. Interestingly, the ageostrophic zonal flow switches sign in the $1^{\circ}$ simulation and this is because there is now subgeostrophic flow near the ITCZ rather than supergeostrophic flow; that is, the pressure gradient acceleration exceeds the Coriolis effect. At this resolution and coarser resolutions, the main meridional momentum balance begins to transition to classical Ekman balance (with horizontal diffusion). Also worth noting is the relative decrease in horizontal diffusion as horizontal resolution increases except for the $1^{\circ}$ simulation; these terms are of secondary importance compared to the other three terms, which better explain regime transitions for each simulation.

\section{March 2009 and March 2010 experiments}

For the following experiments, we force the system (1)-(7) with the YOTC reanalysis boundary layer pressure gradient acceleration averaged over the eastern Pacific Ocean $\left(85^{\circ}-150^{\circ} \mathrm{W}\right)$ for March 2009 and March 2010. Figures 8 and 9 display numerical solutions of $u(\phi, t), v(\phi, t), \zeta(\phi, t)$, and $w(\phi, t)$ in a quasi-steady state for the $0.01^{\circ}$ simulations in the blue curves and the $0.25^{\circ}$ simulations in the red curves of the experiments during March 2009 and March 2010, respectively. Similar to Fig. 4, the black solid curves are the associated YOTC reanalysis fields averaged over the eastern Pacific boundary layer $\left(85^{\circ}-150^{\circ} \mathrm{W}, 950-1000 \mathrm{hPa}\right)$ and the thin black dashed curves are the initial conditions, which satisfy local Ekman balance with the prescribed pressure gradient acceleration. Recall that the eastern Pacific was dominated by a single, near-equatorial ITCZ during March 2010, in contrast with the double (southern dominant)-ITCZ conditions of March 2009 (e.g., TRMM precipitation from Fig. 3). Also, remember from Fig. 2 that the pressure gradient acceleration had slight, but important differences near the equator when compared to March 2009.

From Figs. 8 and 9, it is clear that a double ITCZ is preferred during March 2009 while one primary ITCZ north of the equator is preferred for the pressure gradient observed during March 2010. Similar to the July experiments, the $0.01^{\circ}$ simulations produce the sharpest meridional wind gradients and thus, the most intense vertical motion and cyclonic vorticity in the ITCZ.

Comparing the $0.25^{\circ}$ simulation with YOTC for March 2009, there is a region of rising motion at $4^{\circ}-5^{\circ}$ off of the equator in each hemisphere (Fig. 8). The ITCZ south of the equator is slightly stronger than the one north of the equator, with a maximum rising motion of 4-5 $\mathrm{mm} \mathrm{s}^{-1}$ compared to $3-4 \mathrm{~mm} \mathrm{~s}^{-1}$ for the northern ITCZ. The $0.01^{\circ}$ simulation shows a more intense southern ITCZ, with a maximum vertical velocity concentrated near $5^{\circ} \mathrm{S}$ of $34 \mathrm{~mm} \mathrm{~s}^{-1}$. Like the vertical velocity field, there is very intense and narrow cyclonic vorticity in the ITCZ (a vorticity sheet) in the $0.01^{\circ}$ simulation, which suggests that the southern ITCZ was significantly more intense than the northern ITCZ. The cyclonic vorticity centers are associated with weakening easterlies approaching the equatorial region, with the slab boundary layer model simulations producing larger meridional gradients and thus, larger cyclonic vorticity than YOTC. The narrowness and intensity of the southern ITCZ produced by the $0.01^{\circ}$ simulation during March 2009 is supported by the TRMM precipitation estimates shown in Fig. 3; even though there was a double ITCZ at times, the southern ITCZ was typically stronger and more concentrated. This is an example of how higher-resolution simulations can elucidate crucial features of the nonlinear dynamics associated with the ITCZ. 

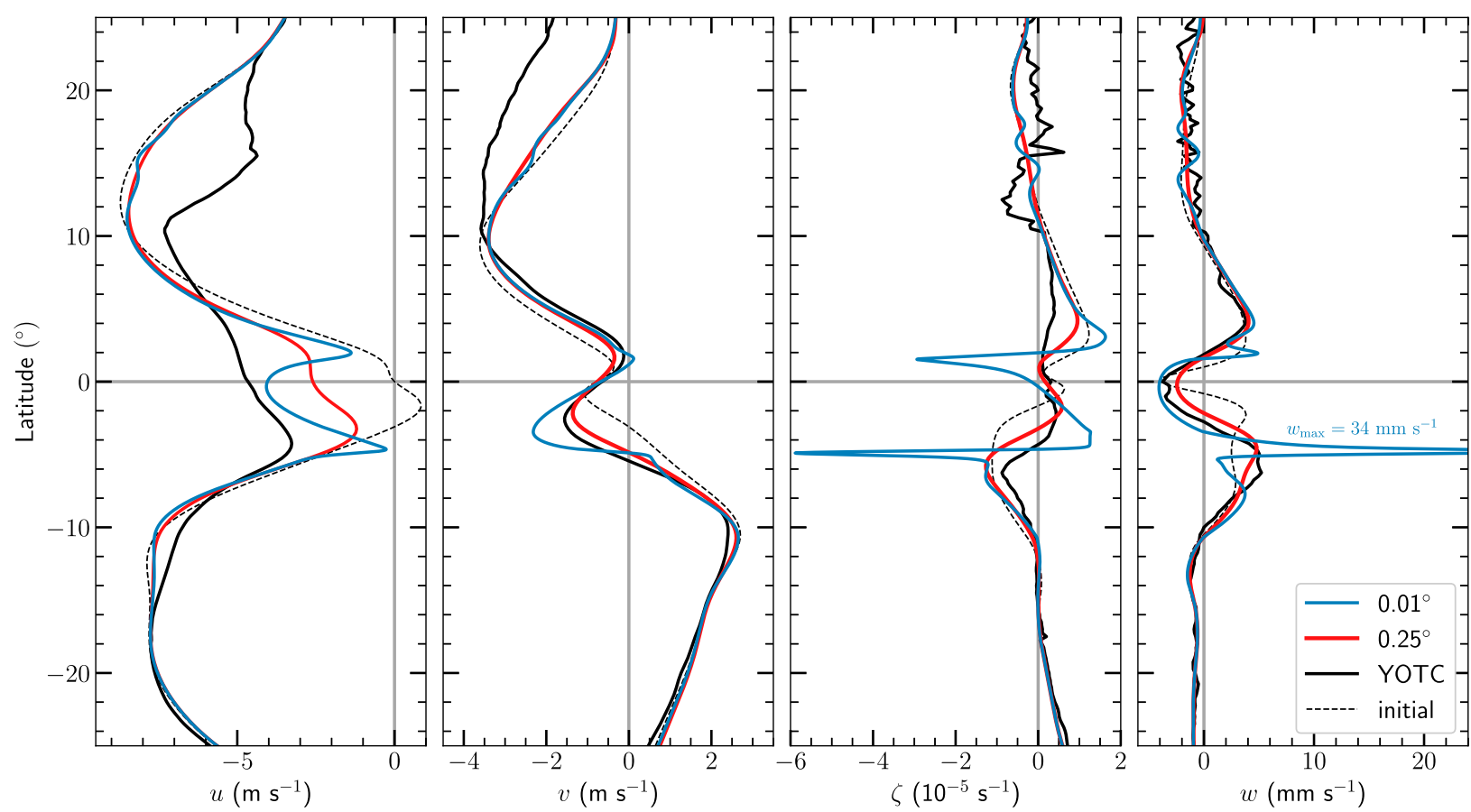

FIG. 8. Quasi-steady-state solutions of the slab boundary layer model at $0.01^{\circ}$ (blue curves) and $0.25^{\circ}$ (red curves) resolution forced by the March 2009 YOTC pressure gradient acceleration. Also displayed are the Ekman balance initial conditions for each field (thin black dashed curves); see (B2) and (B3) for details. The monthly, $85^{\circ}-150^{\circ} \mathrm{W}$, and boundary layer (950-1000 hPa)-averaged YOTC fields are represented by the black solid curves.

For the March 2010 experiments, Fig. 9 shows a broad region of convergence surrounding the equator in the $0.01^{\circ}$ simulation similar to the $0.25^{\circ}$ run and the YOTC reanalysis, but a much narrower concentration of vertical velocity near $3^{\circ} \mathrm{N}$, with a maximum of $60 \mathrm{~mm} \mathrm{~s}^{-1}$. This spike in vertical velocity is associated with a near discontinuity in meridional velocity, where $2 \mathrm{~m} \mathrm{~s}^{-1}$ southerlies abruptly switch to $1 \mathrm{~m} \mathrm{~s}^{-1}$ northerlies. At nearly the same location (slightly north), there is a cyclonic vorticity sheet associated with a sharp gradient in zonal flow, wherein the vorticity sheet is approximately an order of magnitude larger than $f$. It is also worth noting that the Ekman balance solutions and the March $20100.01^{\circ}$ simulation do produce two convergence zones, but they are on the same side of the equator, which would not be considered a traditional double ITCZ. Additionally, in contrast to a traditional double ITCZ, there is not a clear subsidence region between the two convergence regions.

Note that the March 2009 Southern Hemisphere ITCZ is mainly explained by a reversal in meridional flow, from southerly to northerly flow whereas the ITCZ in the Northern Hemisphere is primarily a slowdown of northerly flow, with only the $0.01^{\circ}$ simulation showing a very slight reversal in meridional velocity, as shown in Fig. 8. According to surface wind observations of double ITCZs in the eastern Pacific and Atlantic Ocean basins (Liu and
Xie 2002), the stronger of the two ITCZs is typically associated with a reversal in meridional flow and the weaker ITCZ is associated with a slowdown, not reversal, in meridional flow.

Similar to the July 2008 experiments, we perform an analysis of the zonal and meridional momentum budget equations for March 2009 and March 2010 in Figs. 10 and 11 . Outside of the equatorial region $\left(10^{\circ} \mathrm{S}-10^{\circ} \mathrm{N}\right)$, Ekman balance appears to be a reasonable first-order approximation of the zonal and meridional momentum budgets for both March 2009 and March 2010, as illustrated in Figs. 10 and 11. However, near the March 2009 double-ITCZ and March 2010 single-ITCZ convergence regions, horizontal wind advection and horizontal diffusion become increasingly critical processes.

In Figs. 10c, 10d, 11c, and 11d, we zoom into the main convergence regions, that is, the Southern Hemisphere ITCZ for March 2009 and the near-equatorial ITCZ for March 2010. The zonal momentum budgets near the ITCZ for both March 2009 and 2010 are well described by a balance between horizontal diffusion and $-v(\partial u / a \partial \phi)$, with relatively smaller contributions from the Coriolis effect and surface drag.

The meridional momentum budget near the southern ITCZ for March 2009 behaves similarly that of the July 2008 experiments, with the leading term being the 

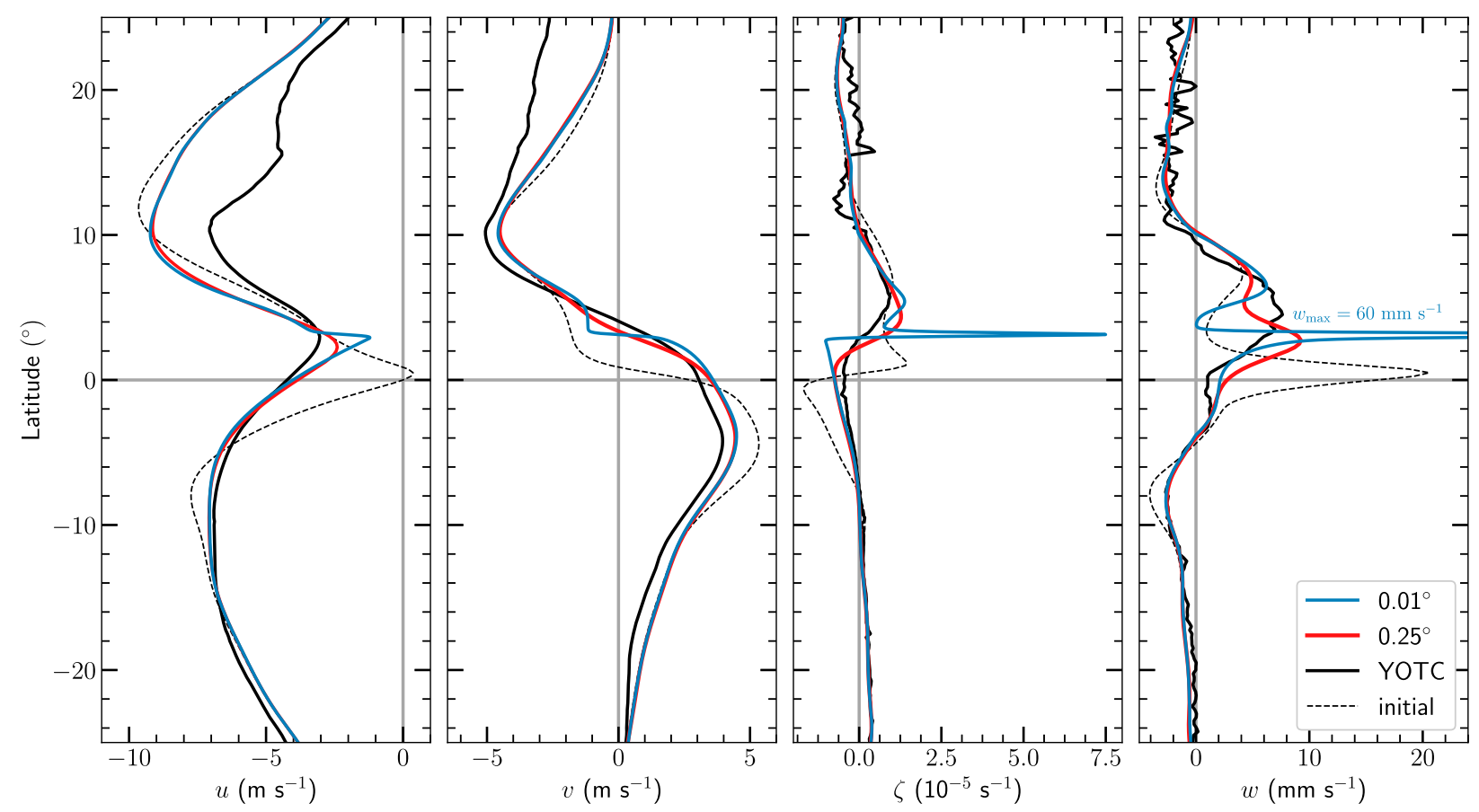

FIG. 9. As in Fig. 8, but for March 2010.

meridional wind advection, $-v(\partial u / a \partial \phi)$, as shown in Figs. 10c and 10d. Balancing the meridional advection near the region of sharp gradients is the so-called ageostrophic Coriolis term, which is the sum of the pressure gradient acceleration and the Coriolis effect. Diffusion and surface drag also counteract horizontal advection but they have smaller contributions to the budget. Since horizontal diffusion is not the primary process that balances meridional advection, we can say that the Southern Hemisphere ITCZ of March 2009 is not considered shocklike. Despite this caveat, it is clear that Ekman balance is violated near the equator due to the critical role of horizontal wind advection near the Southern Hemisphere ITCZ.

Zooming into the main convergence region for the meridional momentum budget for March 2010 in Figs. 11c and 11d illustrates that meridional advection of the meridional wind is the leading term with horizontal diffusion nearly balancing horizontal wind advection. This is indicative of a shocklike structure, similar to the one produced in Gonzalez et al. (2016) for a single, on-equatorial ITCZ (their Fig. 8). Note that the combined pressure gradient and Coriolis term does oppose horizontal advection and has a nonnegligible contribution. However, it seems that for ITCZs this close to the equator, the ageostrophic Coriolis term does not play as large of a role in counteracting meridional advection as horizontal diffusion. Therefore, the main process preventing a discontinuity from occurring is indeed the horizontal diffusion, in line with the concept of a Burgers shock.
It is worth noting that the simulation that produced a shocklike structure in Gonzalez et al. (2016) was a simple case of a pressure gradient forcing associated with boundary layer easterlies centered on the equator with quasi-steady-state solutions of weakened easterlies centered about the equator surrounded by one maximum in easterlies in each hemisphere (their Fig. 3). The March 2010 solutions also had weakened easterlies near the equator surrounded by one maximum in easterlies in each hemisphere. However, March 2009 had strictly easterlies too and a double ITCZ was produced even though in Gonzalez et al. (2016) equatorial westerlies appeared to be strongly associated with a double ITCZ. Despite this caveat, the $0.01^{\circ}$ and $0.25^{\circ}$ March 2009 simulations do have a westerly bias near the equator when compared to the YOTC zonal winds. Whether this equatorial zonal wind model bias represents something more realistic for the transient behavior of the ITCZ than the monthly averaged YOTC fields is yet to be determined.

\section{Dependence of single and double boreal spring ITCZs on horizontal resolution}

A figure similar to Fig. 6 is produced in Fig. 12 for March 2009 showing that the ITCZ intensifies as horizontal resolution increases in the slab boundary layer model. In lower-resolution runs $\left(\geq 0.25^{\circ}\right)$, there appears to be one ITCZ in each hemisphere of similar magnitude whereas in reality, the ITCZ south of the equator was typically much more intense than the one north of the 


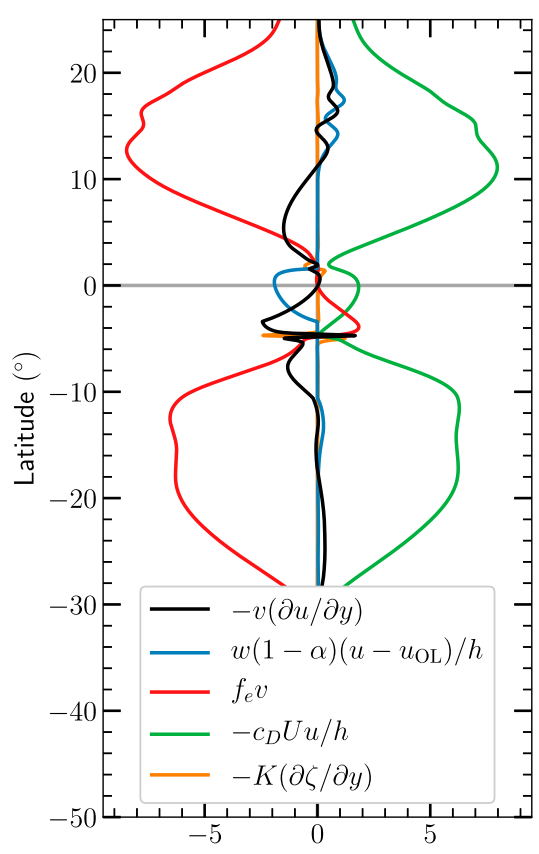

a) $\partial u / \partial t$ terms $\left(\mathrm{m} \mathrm{s}^{-1} \mathrm{~d}^{-1}\right)$

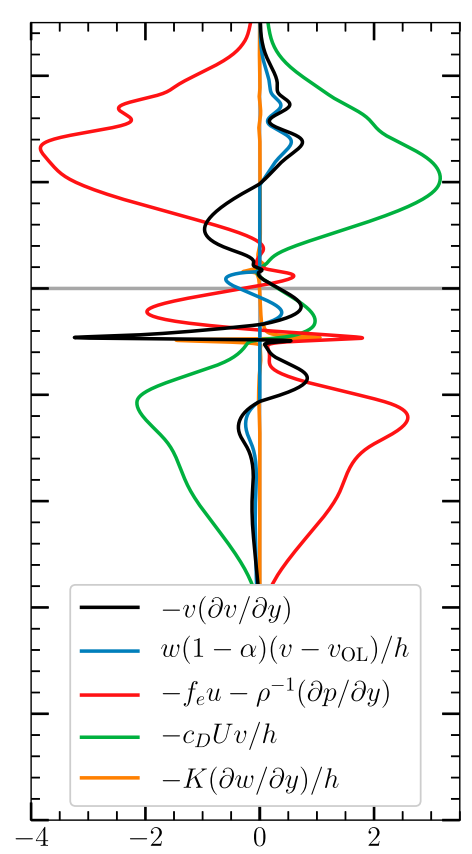

b) $\partial v / \partial t$ terms $\left(\mathrm{m} \mathrm{s}^{-1} \mathrm{~d}^{-1}\right)$

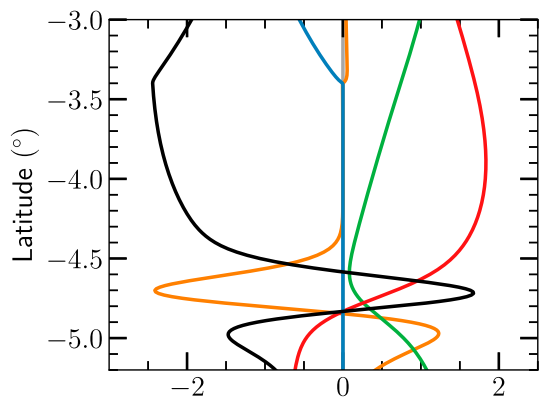

c) $\partial u / \partial t$ terms $\left(\mathrm{m} \mathrm{s}^{-1} \mathrm{~d}^{-1}\right)$

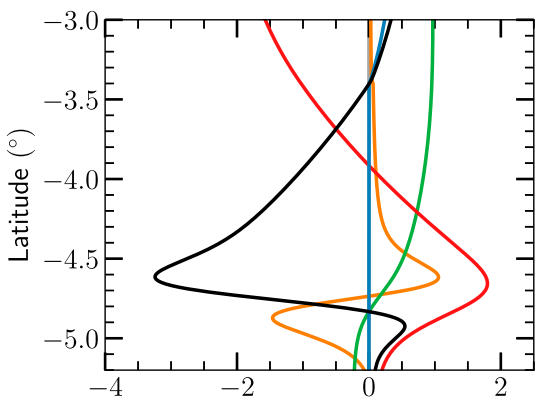

d) $\partial v / \partial t$ terms $\left(\mathrm{m} \mathrm{s}^{-1} \mathrm{~d}^{-1}\right)$

FIG. 10. (a),(b) The quasi-steady-state contributions of the individual terms on the right-hand sides of (10) and (11) for the March 2009 YOTC forcing at a horizontal resolution of $0.01^{\circ}$. (c),(d) Magnification of the region of sharp gradients $\left(4.2^{\circ}-5.3^{\circ} \mathrm{S}\right)$ in $(\mathrm{a})$ and (b), respectively. Note the shorthand notations $y=a \phi$ and $f_{e}=2 \Omega \sin \phi+u \tan \phi / a$.

equator (see center panel of Fig. 3). The stronger ITCZ to the south is only reproduced in the two highestresolution runs $\left(\leq 0.05^{\circ}\right)$. In addition, the subsidence region near the equator intensifies significantly as horizontal resolution increases. These results suggest that the differences between single and double ITCZs may depend on horizontal resolution due to more accurately resolved nonlinear boundary layer dynamics.

The dependence of ITCZ intensity and width on horizontal resolution for the March 2010 experiments was addressed by producing a figure similar to Figs. 6 and 12 but it has been omitted for brevity. It is in general agreement with Figs. 6 and 12, showing that the ITCZ intensifies as horizontal resolution increases in the slab boundary layer model. Unlike the March 2009 case, the slab boundary layer model produces one main ITCZ centered north of the equator for all resolutions tested. However, an ITCZ vorticity sheet is only produced for the two highest-resolution simulations $\left(0.01^{\circ}\right.$ and $\left.0.05^{\circ}\right)$.

\section{Comparison of slab boundary layer and YOTC momentum budgets}

From our comparison between the YOTC monthly fields and the slab model simulations, it is difficult to determine whether or not the high-resolution $\left(\leq 0.05^{\circ}\right)$ slab model simulations are realistic. This is because even though the YOTC reanalysis contains observations, there are observational gaps over the eastern Pacific Ocean boundary layer. Therefore, YOTC is largely a model over this region and the boundary layer fields are likely dependent on model horizontal resolution.

To more objectively quantify the differences between the slab boundary layer model simulation quasi-steadystate solutions and the monthly averaged fields from YOTC, we compute the $10^{\circ} \mathrm{S}-10^{\circ} \mathrm{N}$ root-mean-square differences (RMSDs) of the zonal and meridional momentum budgets between YOTC $\left(\approx 0.25^{\circ}\right)$ and the $0.25^{\circ}$ model simulations in Table 2. We show the RMSDs of the most critical terms in the zonal and meridional momentum budgets: 1) the meridional advection of the horizontal winds $v(\partial u / \partial y), v(\partial v / \partial y), 2)$ the effective Coriolis terms $f_{e} v, f_{e} u$, and 3$)$ the surface drag terms $\left(c_{D} U u / h\right)$, $\left(c_{D} U v / h\right)$ for July 2008, March 2009, and March 2010. In addition, we show the meridional distribution of the three leading terms in the zonal and meridional momentum budgets for all three $0.25^{\circ}$ simulations and the monthly averaged fields from YOTC in Fig. 13 to have a more detailed comparison of the shape and amplitude of the differences between the slab model solutions and the YOTC fields. For the meridional momentum budget comparison plots, we show $-f_{e} u-\rho^{-1}(\partial p / \partial y)$ (where the pressure gradient acceleration is the same for YOTC and the slab model) rather than $-f_{e} u$ in order 


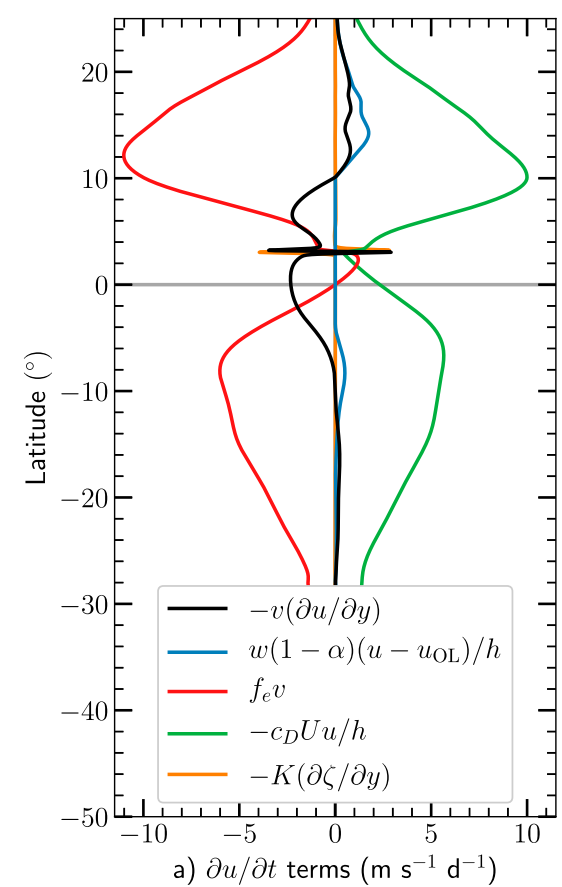

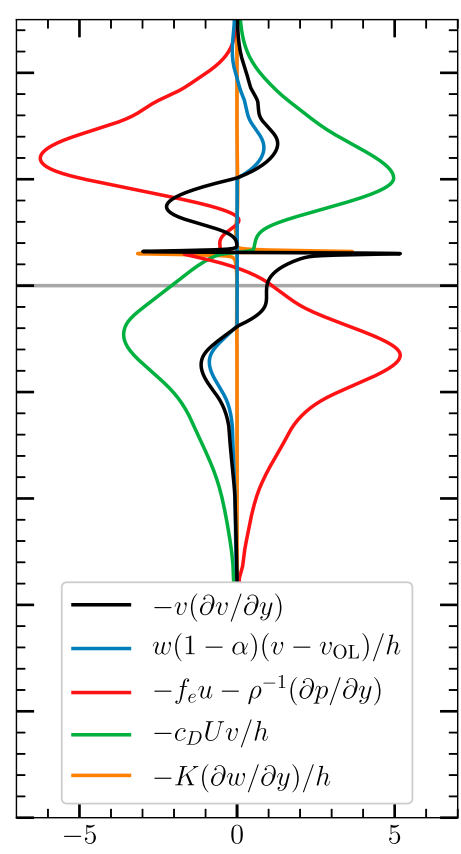

b) $\partial v / \partial t$ terms $\left(\mathrm{m} \mathrm{s}^{-1} \mathrm{~d}^{-1}\right)$
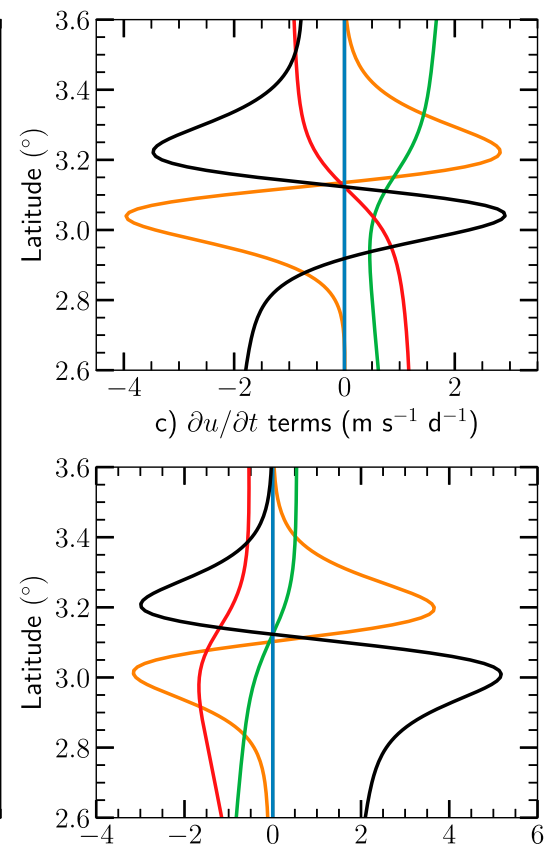

d) $\partial v / \partial t$ terms $\left(\mathrm{m} \mathrm{s}^{-1} \mathrm{~d}^{-1}\right)$

FIG. 11. As in Fig. 10, but for March 2010, and the region of sharp gradients is $2.6^{\circ}-3.5^{\circ} \mathrm{N}$.

to make this term a similar magnitude as the other two terms.

The RMSDs and the meridional plots suggest that the largest differences between YOTC and the slab model are in the zonal winds, such that $c_{D} U u / h$ and $f_{e} u$ are the terms with the largest RMSDs $(1.23,1.84)$ for the zonal and meridional momentum budgets, respectively. The differences in these momentum terms between YOTC and the slab model appear to be related more to the amplitude rather than the shape of the curves $\left(10^{\circ} \mathrm{S}-\right.$ $10^{\circ} \mathrm{N}$ correlation coefficients are all above 0.91 ). The other terms, which depend more on $v$ than $u$, are represented quite well by the slab boundary layer model, with RMSDs one order of magnitude smaller than the RMSDs of $c_{D} U u / h$ and $f_{e} u$. Interestingly, the meridional advective terms have the smallest RMSDs, with average values of 0.24 and 0.17 for the zonal and meridional momentum budgets, respectively. The results from our analysis imply that the slab model could be improved in its representation of the zonal winds but it simulates realistic meridional winds and it is not overestimating the meridional advective terms $v(\partial u / \partial y), v(\partial v / \partial y)$, which are crucial to the development of the ITCZ in our simulations, especially in the high-resolution $\left(\leq 0.05^{\circ}\right)$ simulations.

\section{Concluding remarks}

The ITCZ is a critical component of the climate system; together with the Hadley circulation, they transport moisture, momentum, and energy from the tropics to the extratropics. Despite the ITCZ's significance in our climate, there are numerous unanswered questions about its basic features, such as its variability with respect to ocean basin and season, its width, and its strength. Motivated by these outstanding issues related to the ITCZ and recent studies that have suggested the critical mechanisms explaining ITCZ features, this study further investigates core processes of the ITCZ using an idealized (slab, subcloud, zonally symmetric) boundary layer numerical model. Using the relatively high-resolution YOTC reanalysis to force the slab boundary layer model, we are able to confirm that the eastern Pacific ITCZ boundary layer often does not conform to classic Ekman balance, particularly near the region of most intense convergence (and convection). Instead, the boundary layer heavily involves horizontal wind advection, which leads to dynamical nonlinearities that are dependent on model resolution and cannot be described using a traditional scale analysis.

We have illustrated one way in which the width of the low-level convergence associated with the ITCZ can be explained by dry dynamics, that is, by the formation of a sharp gradient or shocklike structure in the boundary layer meridional flow, with northerly flow on the north edge of the ITCZ and southerly flow on the south edge of the ITCZ. Nonetheless, there are other physical processes occurring near the ITCZ that we have not addressed, such as how strong cross-equatorial moisture 

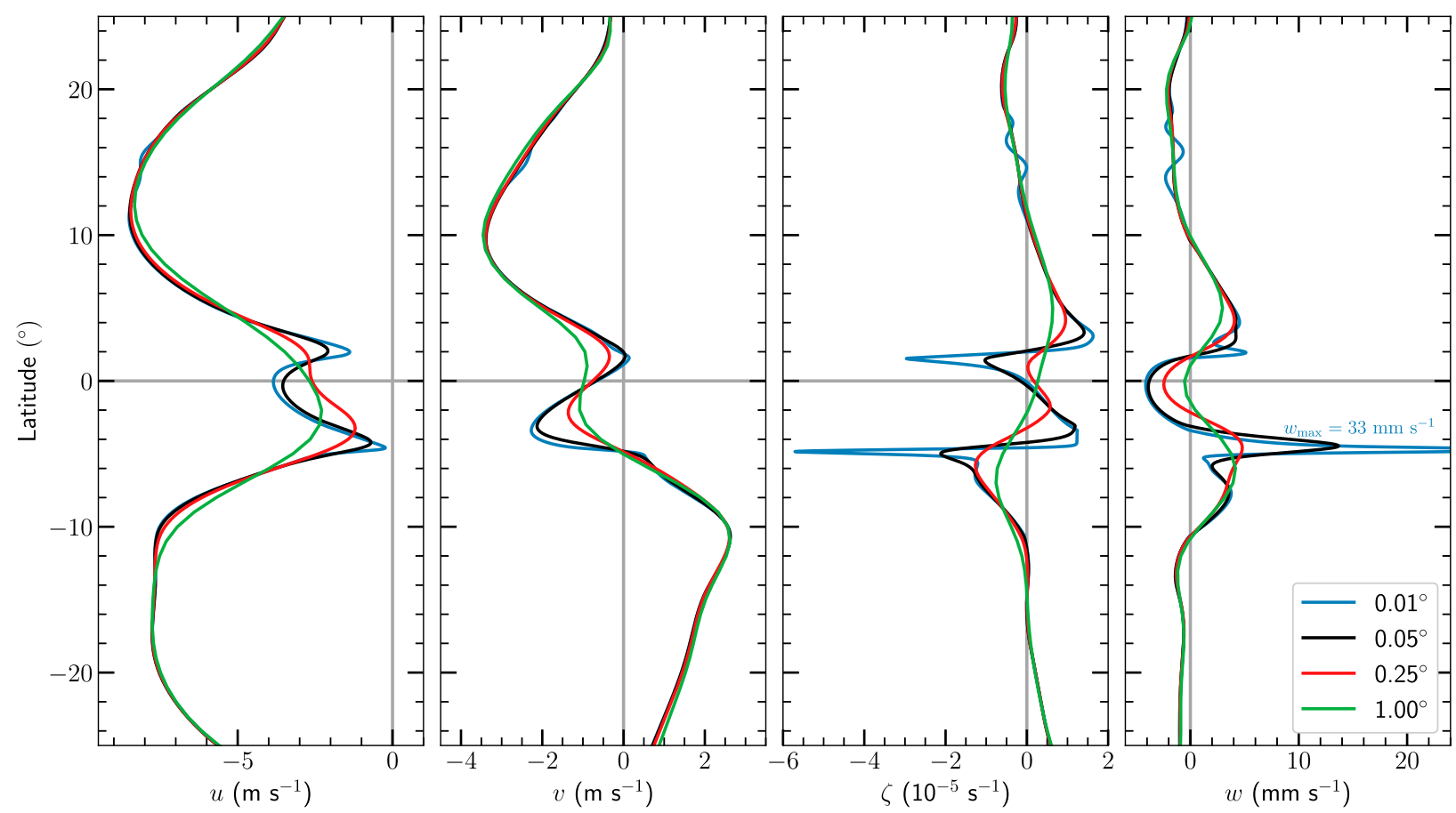

FIG. 12. The slab boundary layer model quasi-steady-state solutions for the March 2009 YOTC forcing at the four horizontal resolutions of $0.01^{\circ}, 0.05^{\circ}, 0.25^{\circ}$, and $1^{\circ}$. For details about the constants used in the different model simulations, refer to Table 1 .

gradients and the meridional advection of moisture impact the localization and width of the ITCZ (e.g., Raymond et al. 2006; Sobel and Neelin 2006). In this paper, we suggest that the localization and width of rising motions in the ITCZ are associated with the $v(\partial v / a \partial \phi)$ term in the meridional momentum equation due to the presence of an embedded Burgers effect that can lead to sharp gradients and shocklike structures in the meridional direction. Since $v$ is an order of magnitude larger in the boundary layer than in the overlying fluid (approximately 5 versus $0.5 \mathrm{~m} \mathrm{~s}^{-1}$ ), sharp gradients and shocklike structures are primarily a phenomenon of the boundary layer. Additionally, the boundary layer meridional winds are sufficiently large enough for Burgers effect to play an important role in the ITCZ of eastern ocean basins, such as the eastern Pacific and eastern Atlantic, where narrow zonally elongated ITCZs are observed in nature. However, it is possible that other tropical ocean basins, such as the IndoPacific warm pool, have smaller meridional winds that do not meet the necessary requirements for meridional gradient sharpening to occur as readily. This may partially explain why the ITCZs in these regions tend to be broader in area and have weaker low-level convergence than those in the eastern Atlantic and eastern Pacific.

Another important result of this study is that the ITCZ transitions from an Ekman to advective boundary layer as one approaches the ITCZ; this implies that the nearby region is not always in a steady state and may experience substantial transient day-to-day changes in the zonal and meridional momentum budget. Surprisingly, over 40 years ago, Mahrt (1972a,b) noted the transition from an Ekman to advective boundary layer in relatively coarse-resolution $(\approx 50 \mathrm{~km})$ simulations of the tropical boundary layer. The relevance of transient advective terms near the equator is in general agreement with observations of the ITCZ, where it has been shown that the ITCZ exhibits dynamic daily to weekly variability due to a vigorous diurnal cycle (Deser and Smith 1998; Bain et al. 2010; Ciesielski et al. 2018), ITCZ breakdown (Ferreira and Schubert 1997; Wang and Magnusdottir 2006; Magnusdottir and Wang 2008), and subseasonal shifts between single and double ITCZs during boreal spring (Henke et al. 2012; Haffke et al. 2016).

TABLE 2. Root-mean-square difference $\left(\mathrm{m} \mathrm{s}^{-1}\right.$ day $\left.^{-1}\right)$ over $10^{\circ} \mathrm{S}-10^{\circ} \mathrm{N}$ between the YOTC reanalysis (monthly mean, $0.25^{\circ}$ ) and the $0.25^{\circ}$ slab boundary layer model simulation quasi-steady state for the three leading terms: nonlinear surface drag, meridional advection, and Coriolis effect, in the zonal and meridional momentum budgets.

\begin{tabular}{lcccccc}
\hline \multicolumn{1}{c}{ Expt } & $c_{D} U(u / h)$ & $v(\partial u / \partial y)$ & $f_{\mathrm{e}} v$ & $c_{D} U(v / h)$ & $v(\partial v / \partial y)$ & $f_{\mathrm{e}} u$ \\
\hline July 2008 & 0.70 & 0.26 & 0.43 & 0.10 & 0.22 & 1.72 \\
March 2009 & 1.16 & 0.24 & 0.08 & 0.05 & 0.04 & 1.14 \\
March 2010 & 1.84 & 0.22 & 0.46 & 0.15 & 0.24 & 2.65 \\
Average & 1.23 & 0.24 & 0.32 & 0.10 & 0.17 & 1.84 \\
\hline
\end{tabular}



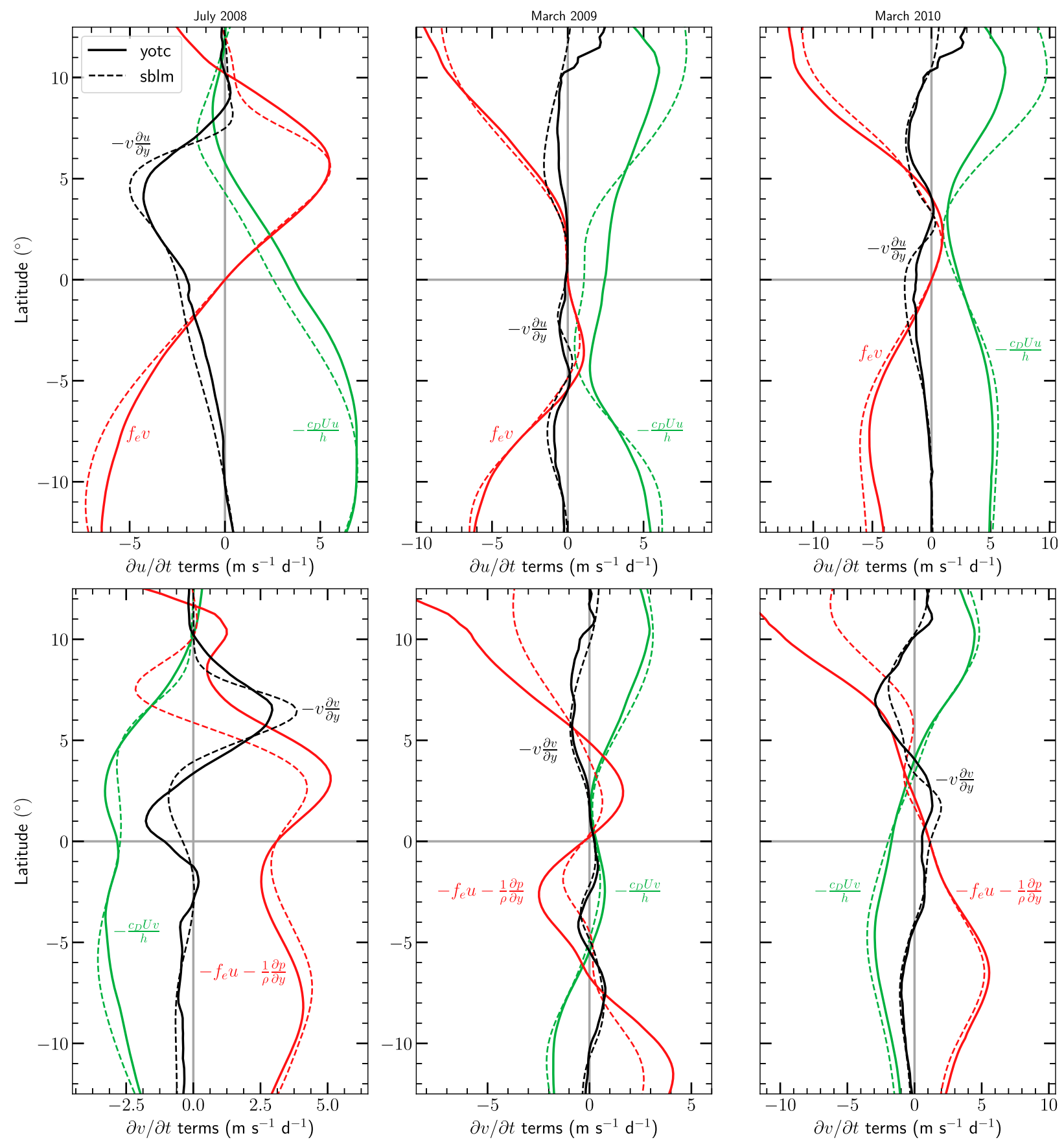

FIG. 13. (top) Zonal and (bottom) meridional momentum budget of the three leading terms (nonlinear surface drag, meridional advection, and Coriolis effect) in the quasi-steady-state solutions of the slab boundary layer model $\left(0.25^{\circ}\right)$ and the YOTC monthly averages for (left) July 2008, (center) March 2009, and (right) March 2010.

If the nonlinear advective boundary layer dynamics in and near the ITCZ that we have highlighted in this study have a substantial impact on ITCZ transients, it is likely that current-day GCMs are not simulating these physical processes accurately, mainly due to their coarse spatial resolution. We suggest that future work focus on interrogating the low-level momentum and moisture budgets of high-resolution GCM simulations as well as the European Centre's new high-resolution reanalysis, ERA5, with a focus on the transient dynamics of the ITCZ. We must better quantify these short-time-scale characteristics of the ITCZ because 
they may help unravel the underlying reasons for GCM biases of the ITCZ.

Additionally, with the recent advent of ITCZ energy balance theories and the perspectives about the ITCZ boundary layer gained from this study and others preceding it, it would be beneficial to try and connect these ideas. However, to do this, a more complete model of the ITCZ must be used since the slab boundary layer model in its present form can only describe the kinetic energy budget and it does not incorporate the upper-level energy transport that is at the heart of parameters such as the energy flux equator. Nonetheless, we have derived the kinetic energy budget for the ITCZ slab boundary layer model in appendix C. It appears more work must be done to connect the outstanding ITCZ theories from the atmosphericoceanic energy balance and boundary layer convergence perspectives (e.g., Faulk et al. 2017; Hill 2019).

In closing, sharp meridional gradients and shocklike structures are features that occur frequently near the ITCZ, particularly narrow ITCZs. Our results suggest that sufficient horizontal resolution is necessary to accurately simulate the horizontal advective terms that lead to the formation of narrow ITCZs, or they must be parameterized in some way.

Acknowledgments. We are grateful for fruitful discussions with Spencer Hill, Jonathan Mitchell, Sean Faulk, Juan Lora, Tapio Schneider, Paul Ciesielski, Rick Taft, and Eric Maloney. We also would like to thank four anonymous reviewers for their careful inspection of our paper. This research has been supported by the National Science Foundation under Grant AGS-1546610 and AGS1841326, under the Science and Technology Center for Multi-Scale Modeling of Atmospheric Processes, managed by Colorado State University through Cooperative Agreement ATM-0425247. The YOTC reanalysis horizontal wind, vorticity, divergence, and geopotential data can be obtained online (http://apps.ecmwf.int/datasets/ data/yotc-od/). The TRMM daily precipitation data can be downloaded online (https://pmm.nasa.gov/data-access/ downloads/trmm/). Also, the slab boundary layer model simulations and all plotting scripts from this study are available from the repository (https://iastate.box.com $/ \mathrm{v} /$ itcz-yotc-repository).

\section{APPENDIX A}

\section{Derivation of Spherical Slab Boundary Layer Model Equations from First Principles}

We begin with the conservation of absolute angular momentum $m=(u+\Omega a \cos \phi) a \cos \phi$. The flux form of the conservation relation is written as

$$
\begin{gathered}
\frac{\partial(h m)}{\partial t}+\frac{\partial(h m v \cos \phi)}{a \cos \phi \partial \phi}+w\left[\alpha m+(1-\alpha) m_{\mathrm{OL}}\right] \\
=-c_{D} U u a \cos \phi+\cos \phi \frac{\partial}{\partial \phi}\left[h K \frac{\partial(u \cos \phi)}{a \cos \phi \partial \phi}\right],
\end{gathered}
$$

where $m_{\mathrm{OL}}=\left(u_{\mathrm{OL}}+\Omega a \cos \phi\right) a \cos \phi$ is the absolute angular momentum in the overlying layer, $(u, v)$ are the respective boundary layer zonal and meridional velocities, $h$ is the depth of the boundary layer, and we define

$$
\alpha=\left\{\begin{array}{lll}
1 & \text { if } \quad w \geq 0 \\
0 & \text { if } \quad w<0
\end{array} .\right.
$$

Refer to section 2 for the definitions of $U$ and $c_{D}$. According to (A1), there are five processes that can alter the absolute angular momentum in the boundary layer of a zonally symmetric atmosphere: 1) meridional divergence of the meridional advective flux of $m, 2$ ) upward flux of $m$ when $w \geq 0,3$ ) downward flux of $m_{\mathrm{OL}}$ when $w<0,4)$ exchange of $m$ with the surface due to surface drag, and 5) meridional divergence of the meridional diffusive flux.

We assume $h$ and $K$ are constants, substitute $m=$ $(u+\Omega a \cos \phi) a \cos \phi$ into (A1), and then divide by $a \cos \phi$, which yields

$$
\begin{aligned}
\frac{\partial u}{\partial t} & +v \frac{\partial u}{a \partial \phi}-\frac{w}{h}(1-\alpha)\left(u-u_{\mathrm{OL}}\right) \\
& =\left(2 \Omega \sin \phi+\frac{u \tan \phi}{a}\right) v-c_{D} U \frac{u}{h}+K \frac{\partial}{a \partial \phi}\left[\frac{\partial(u \cos \phi)}{a \cos \phi \partial \phi}\right] .
\end{aligned}
$$

The derivations of the meridional momentum equation and mass continuity equation proceed in a similar manner as the derivation of absolute angular momentum. The meridional momentum equation in conservation form (before assuming $h$ is constant) is given by

$$
\begin{gathered}
\frac{\partial(h v)}{\partial t}+\frac{\partial(v h v \cos \phi)}{a \cos \phi \partial \phi}+w\left[\alpha v+(1-\alpha) v_{\mathrm{OL}}\right] \\
=-h\left(2 \Omega \sin \phi+\frac{u \tan \phi}{a}\right) u-\frac{h}{\rho} \frac{\partial p}{a \partial \phi} \\
-c_{D} U v+\cos \phi \frac{\partial}{a \partial \phi}\left[h K \frac{\partial(v \cos \phi)}{a \cos \phi \partial \phi}\right],
\end{gathered}
$$

and the mass continuity equation is given by

$$
\frac{\partial h}{\partial t}+\frac{\partial(h v \cos \phi)}{a \cos \phi \partial \phi}+w=0
$$

Assuming that $h$ and $K$ are constants, (2) and (3) immediately follow. 


\section{APPENDIX B}

\section{Classical Ekman Theory Equations}

Gonzalez et al. (2016) suggested that the equations associated with classical Ekman theory are not sufficiently accurate in scenarios when the horizontal advection of the horizontal winds is large. The slab model equations, (1)-(7), can be simplified to a form similar to classical Ekman theory (Ekman 1905) that is insightful for understanding the role of the nonlinearities included in (1) and (2). The classical Ekman theory equations on the sphere are given by

$$
\begin{aligned}
& \left(c_{D} U_{E} / h\right) u_{E}-\left(2 \Omega \sin \phi+\frac{u_{E} \tan \phi}{a}\right) v_{E}=0, \\
& \left(c_{D} U_{E} / h\right) v_{E}+\left(2 \Omega \sin \phi+\frac{u_{E} \tan \phi}{a}\right) u_{E}=-\frac{1}{\rho} \frac{\partial p}{a \partial \phi},
\end{aligned}
$$

where the meridional pressure gradient on the righthand side of (B1) is specified in this study by the YOTC reanalysis. Solving the algebraic equations (B1) for $u_{E}$ and $v_{E}$, we obtain

$u_{E}(\phi)=-\left[\frac{\left(2 \Omega \sin \phi+\frac{u_{E} \tan \phi}{a}\right)}{\left(c_{D} U_{E} / h\right)^{2}+\left(2 \Omega \sin \phi+\frac{u_{E} \tan \phi}{a}\right)^{2}}\right] \frac{1}{\rho} \frac{\partial p}{a \partial \phi}$

$v_{E}(\phi)=-\left[\frac{\left(c_{D} U_{E} / h\right)}{\left(c_{D} U_{E} / h\right)^{2}+\left(2 \Omega \sin \phi+\frac{u_{E} \tan \phi}{a}\right)^{2}}\right] \frac{1}{\rho} \frac{\partial p}{a \partial \phi}$,

where the local time derivative terms, the meridional advection terms, the vertical velocity terms, and the horizontal diffusion terms have been neglected. Equations (B2) and (B3) are implicit relations for $u$ and $v$ because of the $u \tan \phi / a$ terms and the dependence of $c_{D} U_{E}$ on $u_{E}$ and $v_{E}$ through (5) and (6). To accept these solutions as self-consistent approximations of the full slab boundary layer model equations, a condition that must be satisfied is $|v(\partial v / a \partial \phi)| \ll \mid(1 / \rho)(\partial \rho / a \partial \phi)$.

The slab Ekman layer solutions, (B2) and (B3), are quite elegant in the sense that they are "local" solutions. This is because $u_{E}(\phi)$ and $v_{E}(\phi)$ at a point in $\phi$ depend only on the meridional pressure gradient at that point. However, as we have demonstrated in this study, the eastern Pacific boundary layer typically does not obey this local Ekman balance near the equator. Therefore, the eastern Pacific
ITCZ should be interpreted as being highly dependent on nonlinearities associated with horizontal advection.

\section{APPENDIX C}

\section{Kinetic Energy Budget}

Even though we cannot calculate an ITCZ predictor such as the energy flux equator in our slab boundary layer model because it only describes kinetic energy evolution ( $h=$ constant), we can gain insight into how kinetic energy evolution and redistribution is related to ITCZ position. A derivation of the energy budget of the slab boundary layer involves the multiplication of (10) by $h u$ and (11) by $h v$ and the addition of the resulting equations, yielding

$$
\frac{\partial \mathscr{K}}{\partial t}=\mathscr{F}_{\phi}+\mathscr{F}_{z}+\mathscr{G}-\mathscr{D},
$$

where $\mathscr{K}=h\left(u^{2}+v^{2}\right) / 2$ is the kinetic energy, $\mathscr{F}_{\phi}=$ $-\sec \phi[\partial(v \mathscr{K} \cos \phi) / \partial y]$ is the meridional convergence of the meridional advective flux of kinetic energy, $\mathscr{F}_{z}=-(\mathscr{K} w / h)+w(1-\alpha)\left[u\left(u-u_{\mathrm{OL}}\right)+v\left(v-v_{\mathrm{OL}}\right)\right]$ is the vertical flux of kinetic energy at the top of the boundary layer, $\mathscr{G}=-(h v / \rho)(\partial p / \partial y)$ is the generation of kinetic energy through southerly flow up the pressure gradient and northerly flow down the pressure gradient (commonly known as pressure work), and $\mathscr{D}=\left(2 c_{D} U \mathscr{K} / h\right)+K h u(\partial \zeta / \partial y)+K v(\partial w / \partial y)$ is the dissipation of kinetic energy through surface drag and meridional diffusion, respectively.

In all of our simulations, the energy budget of the quasi-steady-state ITCZ boundary layer is mainly described by a balance between the generation of kinetic energy by $\mathscr{G}$ and the dissipation of kinetic energy by the surface drag terms in $\mathscr{D}$, as illustrated in Fig. C1. However, near the ITCZs, the $\mathscr{F}_{\phi}$ and $\mathscr{F}_{z}$ terms can increase substantially in magnitude, especially for the July 2008 simulation. In these regions, there is typically a generation of kinetic energy by $\mathscr{F}_{\phi}$ through the meridional advection of kinetic energy and a dissipation of kinetic energy by $\mathscr{F}_{\phi}$ through the vertical advection of kinetic energy via rising motion at the top of the boundary layer. When attempting to assess a predictor for ITCZ position in one of the kinetic energy budget terms, it appears that ITCZ is typically located quite close to where $\mathscr{G}=0$, especially for the July 2008 simulation. However, there are often multiple latitudes where $\mathscr{G}$ crosses zero, such as in the March simulations, due to the pressure gradient acceleration and meridional velocity not always crossing zero at the same latitude. Therefore, the latitude at which $\mathscr{G}$ crosses zero might 

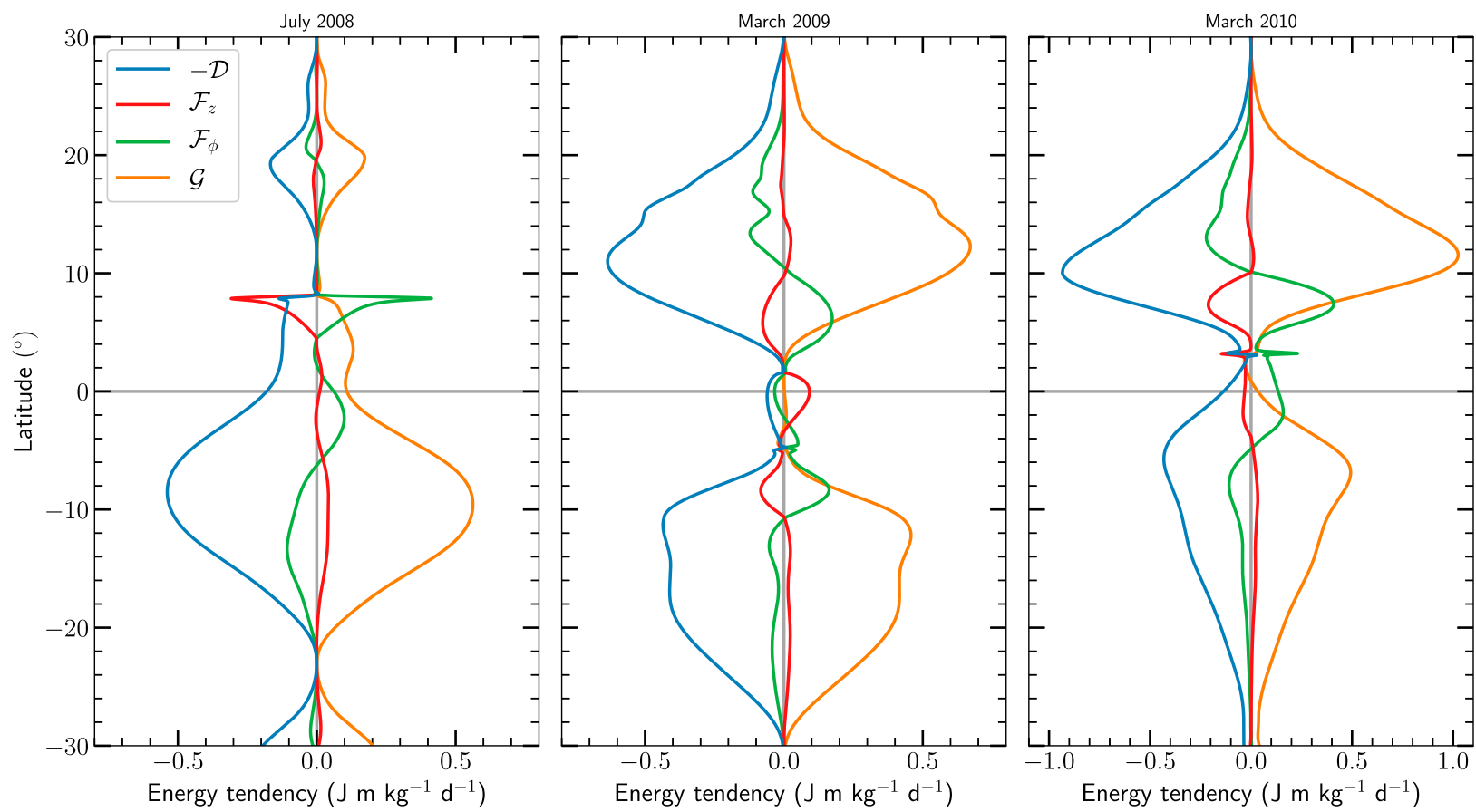

FIG. C1. The $0.01^{\circ}$ slab boundary layer model quasi-steady-state solutions of the energy budget terms $\mathscr{G}_{,} \mathscr{F}_{\phi}, \mathscr{F}_{z},-\mathscr{D}$ from $(\mathrm{C} 1)$ for (left) July 2008, (center) March 2009, and (right) March 2010.

be a useful ITCZ predictor for cases when the ITCZ is farther away from the equator (e.g., July 2008) but it can have issues when the ITCZ is positioned closer the equator or a double ITCZ exists (e.g., March 2009 and March 2010).

\section{REFERENCES}

Adam, O., T. Bischoff, and T. Schneider, 2016a: Seasonal and interannual variations of the energy flux equator and ITCZ. Part I: Zonally averaged ITCZ position. J. Climate, 29, 3219-3230, https://doi.org/10.1175/JCLI-D-15-0512.1.

$\longrightarrow,-$, and 2016b: Seasonal and interannual variations of the energy flux equator and ITCZ. Part II: Zonally varying shifts of the ITCZ. J. Climate, 29, 7281-7293, https://doi.org/ 10.1175/JCLI-D-15-0710.1.

Back, L. E., and C. S. Bretherton, 2009: On the relationship between SST gradients, boundary layer winds, and convergence over the tropical oceans. J. Climate, 22, 4182-4196, https:// doi.org/10.1175/2009JCLI2392.1.

Bain, C. L., G. Magnusdottir, P. Smyth, and H. Stern, 2010: Diurnal cycle of the intertropical convergence zone in the east Pacific. J. Geophys. Res., 115, D23116, https://doi.org/10.1029/2010JD014835.

Bischoff, T., and T. Schneider, 2014: Energetic constraints on the position of the intertropical convergence zone. J. Climate, 27, 4937-4951, https://doi.org/10.1175/JCLI-D-13-00650.1.

- , and 2016: The equatorial energy balance, ITCZ position, and double-ITCZ bifurcations. J. Climate, 29, 2997-3013, https://doi.org/10.1175/JCLI-D-15-0328.1.

Broccoli, A. J., K. A. Dahl, and R. J. Stouffer, 2006: Response of the ITCZ to Northern Hemisphere cooling. Geophys. Res. Lett., 33, L01702, https://doi.org/10.1029/2005GL024546.
Burgers, J. M., 1948: A mathematical model illustrating the theory of turbulence. Adv. Appl. Mech., 1, 171-199, https://doi.org/ 10.1016/S0065-2156(08)70100-5.

Byrne, M. P., and T. Schneider, 2016a: Energetic constraints on the width of the intertropical convergence zone. J. Climate, 29, 4709-4721, https://doi.org/10.1175/JCLI-D-15-0767.1.

$\ldots$, and _ 2016b: Narrowing of the ITCZ in a warming climate: Physical mechanisms. Geophys. Res. Lett., 43, 11350 11357, https://doi.org/10.1002/2016GL070396.

Charney, J. G., 1969: The intertropical convergence zone and the Hadley circulation of the atmosphere. Proc. WMO/IUGG Symp. on Numerical Weather Prediction, Tokyo, Japan, Japanese Meteorological Agency, 73-79.

Ciesielski, P. E., R. H. Johnson, W. H. Schubert, and J. H. Ruppert, 2018: Diurnal cycle of the ITCZ in DYNAMO. J. Climate, 31, 4543-4562, https://doi.org/10.1175/JCLI-D-17-0670.1.

Deser, C., and C. A. Smith, 1998: Diurnal and semidiurnal variations of the surface wind field over the tropical Pacific Ocean. J. Climate, 11, 1730-1748, https://doi.org/10.1175/15200442(1998)011<1730:DASVOT>2.0.CO;2.

ECMWF, 2012: YOTC operational data retrieval. ECMWF, accessed 23 March 2017, https://apps.ecmwf.int/datasets/data/yotc-od/.

Ekman, V. W., 1905: On the influence of the Earth's rotation on ocean currents. Ark. Mat. Astron. Fys., 2, 1-52.

Faulk, S., J. Mitchell, and S. Bordoni, 2017: Effects of rotation rate and seasonal forcing on the ITCZ extent in planetary atmospheres. J. Atmos. Sci., 74, 665-678, https://doi.org/10.1175/JAS-D-16-0014.1.

Ferreira, R. N., and W. H. Schubert, 1997: Barotropic aspects of ITCZ breakdown. J. Atmos. Sci., 54, 261-285, https://doi.org/ 10.1175/1520-0469(1997)054<0261:BAOIB >2.0.CO;2.

Gonzalez, A. O., C. J. Slocum, R. K. Taft, and W. H. Schubert, 2016: Dynamics of the ITCZ boundary layer. J. Atmos. Sci., 73, 1577-1592, https://doi.org/10.1175/JAS-D-15-0298.1. 
Gottlieb, S., C.-W. Shu, and E. Tadmor, 2001: Strong stabilitypreserving high-order time discretization methods. SIAM Rev., 43, 89-112, https://doi.org/10.1137/S003614450036757X.

Green, B., and J. Marshall, 2017: Coupling of trade winds with ocean circulation damps ITCZ shifts. J. Climate, 30, 4395-4411, https://doi.org/10.1175/JCLI-D-16-0818.1.

Haffke, C., G. Magnusdottir, D. Henke, P. Smyth, and Y. Peings, 2016: Daily states of the March-April east Pacific ITCZ in three decades of high-resolution satellite data. J. Climate, 29, 2981-2995, https://doi.org/10.1175/JCLI-D-15-0224.1.

Henke, D., P. Smyth, C. Haffke, and G. Magnusdottir, 2012: Automated analysis of the temporal behavior of the double intertropical convergence zone over the east Pacific. Remote Sens. Environ., 123, 418-433, https://doi.org/10.1016/j.rse.2012.03.022.

Hill, S. A., 2019: Theories for past and future monsoon rainfall changes. Curr. Climate Change Rep., 5, 160-171, https:// doi.org/10.1007/s40641-019-00137-8.

Holton, J. R., 1975: On the influence of boundary layer friction on mixed Rossby-gravity waves. Tellus, 27, 107-115, https:// doi.org/10.3402/tellusa.v27i2.9893.

Huffman, G. J., and D. T. Bolvin, 2015: TRMM and other data precipitation data set documentation. NASA Goddard Space Flight Center Tech. Rep., 44 pp., https://pmm.nasa.gov/sites/ default/files/document_files/3B42_3B43_doc_V7.pdf.

Janota, P., 1971: An empirical study of the planetary boundary layer in the vicinity of the intertropical convergence zone. Ph.D. thesis, Massachusetts Institute of Technology, 279 pp.

Johnson, R. H., P. E. Ciesielski, and J. A. Cotturone, 2001: Multiscale variability of the atmospheric mixed layer over the western Pacific warm pool. J. Atmos. Sci., 58, 2729-2750, https://doi.org/ 10.1175/1520-0469(2001)058<2729:MVOTAM >2.0.CO;2.

Kang, S. M., I. M. Held, D. M. W. Frierson, and M. Zhao, 2008: The response of the ITCZ to extratropical thermal forcing: Idealized slab-ocean experiments with a GCM. J. Climate, 21, 3521-3532, https://doi.org/10.1175/2007JCLI2146.1.

Large, W. G., J. C. McWilliams, and S. C. Doney, 1994: Oceanic vertical mixing: A review and a model with a nonlocal boundary layer parameterization. Rev. Geophys., 32, 363-403, https://doi.org/10.1029/94RG01872.

Lietzke, C. E., C. Deser, and T. H. Vonder Haar, 2001: Evolutionary structure of the eastern Pacific double ITCZ based on satellite moisture profile retrievals. J. Climate, 14, 743-751, https://doi.org/10.1175/1520-0442(2001)014<0743:ESOTEP > 2.0.CO;2.

Lin, J.-L., 2007: The double-ITCZ problem in IPCC AR4 coupled GCMs: Ocean-atmosphere feedback analysis. J. Climate, 20, 4497-4525, https://doi.org/10.1175/JCLI4272.1.

Lindzen, R. S., and S. Nigam, 1987: On the role of sea surface temperature gradients in forcing low-level winds and convergence in the tropics. J. Atmos. Sci., 44, 2418-2436, https://doi.org/10.1175/ 1520-0469(1987)044<2418:OTROSS >2.0.CO;2.

Liu, W. T., and X. Xie, 2002: Double intertropical convergence zones-A new look using scatterometer. Geophys. Res. Lett., 29, 2092, https://doi.org/10.1029/2002GL015431.

Magnusdottir, G., and C.-C. Wang, 2008: Intertropical convergence zones during the active season in daily data. J. Atmos. Sci., 65, 2425-2436, https://doi.org/10.1175/2007JAS2518.1.

Mahrt, L. J., 1972a: A numerical study of the influence of advective accelerations in an idealized, low-latitude, planetary boundary layer. J. Atmos. Sci., 29, 1477-1484, https://doi.org/10.1175/ 1520-0469(1972)029<1477:ANSOTI>2.0.CO;2.

_ 1972b: A numerical study of coupling between the boundary layer and free atmosphere in an accelerated low-latitude flow.
J. Atmos. Sci., 29, 1485-1495, https://doi.org/10.1175/15200469(1972)029<1485:ANSOCB > 2.0.CO;2.

Mechoso, C., and Coauthors, 1995: The seasonal cycle over the tropical Pacific in coupled ocean-atmosphere general circulation models. Mon. Wea. Rev., 123, 2825-2838, https://doi.org/ 10.1175/1520-0493(1995)123<2825:TSCOTT>2.0.CO;2.

NASA GSFC, 2015: TRMM 3B42 version 7 research derived daily product (TRMM data downloads). NASA GSFC, accessed 21 May 2018, https://pmm.nasa.gov/data-access/downloads/ trmm/.

Ooyama, K. V., 1997: Footnotes to "conceptual evolution." Preprints, 22nd Conf. on Hurricanes and Tropical Meteorology, Fort Collins, CO, Amer. Meteor. Soc., 13-18.

Pauluis, O., 2004: Boundary layer dynamics and cross-equatorial Hadley circulation. J. Atmos. Sci., 61, 1161-1173, https://doi.org/ 10.1175/1520-0469(2004)061<1161:BLDACH>2.0.CO;2.

Powell, M. D., P. J. Vickery, and T. A. Reinhold, 2003: Reduced drag coefficient for high wind speeds in tropical cyclones. Nature, 422, 279-283, https://doi.org/10.1038/nature01481.

Raymond, D. J., C. S. Bretherton, and J. Molinari, 2006: Dynamics of the intertropical convergence zone of the east Pacific. J. Atmos. Sci., 63, 582-597, https://doi.org/10.1175/JAS3642.1.

Schneider, T., 2017: Feedback of atmosphere-ocean coupling on shifts of the intertropical convergence zone. Geophys. Res. Lett., 44, 11 644-11 653, https://doi.org/10.1002/2017GL075817.

— the seasonal cycle of a Hadley circulation and implications for monsoon dynamics. J. Atmos. Sci., 65, 915-934, https://doi.org/ 10.1175/2007JAS2415.1.

_ T. Tischoff, and G. H. Haug, 2014: Migrations and dynamics of the intertropical convergence zone. Nature, 513, 45-53, https://doi.org/10.1038/nature13636.

Sobel, A. H., and J. D. Neelin, 2006: The boundary layer contribution to intertropical convergence zones in the quasiequilibrium tropical circulation model framework. Theor. Comput. Fluid Dyn., https://doi.org/10.1007/S00162-006-0033-Y.

Stanfield, R. E., and Coauthors, 2016: A quantitative assessment of precipitation associated with the ITCZ in the CMIP5 GCM simulations. Climate Dyn., 47, 1863-1880, https://doi.org/ 10.1007/s00382-015-2937-y.

Stevens, B., J. Duan, J. C. McWilliams, M. Münnich, and J. D. Neelin, 2002: Entrainment, Rayleigh friction, and boundary layer winds over the tropical Pacific. J. Climate, 15, 30-44, https://doi.org/ 10.1175/1520-0442(2002)015<0030:ERFABL > 2.0.CO;2.

Tomas, R. A., J. R. Holton, and P. J. Webster, 1999: The influence of cross-equatorial pressure gradients on the location of nearequatorial convection. Quart. J. Roy. Meteor. Soc., 125, 11071127, https://doi.org/10.1002/qj.1999.49712555603.

Waliser, D. E., and C. Gautier, 1993: A satellite-derived climatology of the ITCZ. J. Climate, 6, 2162-2174, https://doi.org/ 10.1175/1520-0442(1993)006<2162:ASDCOT >2.0.CO;2. , and R. C. J. Somerville, 1994: Preferred latitudes of the intertropical convergence zone. J. Atmos. Sci., 51, 1619-1639, https:// doi.org/10.1175/1520-0469(1994)051<1619:PLOTIC>2.0.CO;2.

, and Coauthors, 2012: The "year" of tropical convection (May 2008-April 2010): Climate variability and weather highlights. Bull. Amer. Meteor. Soc., 93, 1189-1218, https://doi.org/ 10.1175/2011BAMS3095.1.

Wang, C.-C., and G. Magnusdottir, 2006: The ITCZ in the central and eastern Pacific on synoptic time scales. Mon. Wea. Rev., 134, 1405-1421, https://doi.org/10.1175/MWR3130.1.

Wei, H.-H., and S. Bordoni, 2018: Energetic constraints on the ITCZ position in idealized simulations with a seasonal cycle. 
J. Adv. Model. Earth Syst., 10, 1708-1725, https://doi.org/ 10.1029/2018MS001313.

Yin, B., and B. A. Albrecht, 2000: Spatial variability of atmospheric boundary layer structure over the eastern equatorial Pacific. J. Climate, 13, 1574-1592, https://doi.org/10.1175/15200442(2000)013<1574:SVOABL > 2.0.CO;2.

Zeng, X., M. A. Brunke, M. Zhou, C. Fairall, N. A. Bond, and D. H. Lenschow, 2004: Marine atmospheric boundary layer height over the eastern Pacific: Data analysis and model evaluation. J. Climate, 17, 4159-4170, https://doi.org/10.1175/JCLI3190.1. Zhang, C., 2001: Double ITCZs. J. Geophys. Res., 106, $11785-$ 11 792, https://doi.org/10.1029/2001JD900046.

Zhang, X., L. Hailong, and Z. Minghua, 2015: Double ITCZ in coupled ocean-atmosphere models: From CMIP3 to CMIP5. Geophys. Res. Lett., 42, 8651-8659, https://doi.org/10.1002/ 2015 GL065973. 